\title{
Long Distance Agreement in Hindi-Urdu
}

\author{
Rajesh Bhatt (bhatt@cs.utexas.edu)* \\ The University of Texas at Austin
}

\begin{abstract}
This paper provides a new analysis of the phenomenon of Long Distance Agreement in HindiUrdu and argues for a dissociation between case and agreement. Long Distance Agreement involves a verb agreeing with a constituent inside the verb's clausal complement. Long Distance Agreement and Object Agreement in Hindi-Urdu are shown to involve the same structural configurations. They both involve a head $\left(\mathrm{T}^{0}\right)$ agreeing with an argument whose case-features $\mathrm{T}^{0}$ does not value. In particular it is argued the operation Agree of Chomsky $(1998,1999,2001)$ needs to be reformulated to be able to handle the facts of Hindi-Urdu Long Distance Agreement. The analysis is largely motivated on the basis of evidence from Hindi-Urdu but is shown to extend to the Long Distance Agreement facts of Tsez (Polinsky and Potsdam (2001)) and Kashmiri (Subbarao and Munshi (2000)).
\end{abstract}

Keywords: Agree, Agreement, Case, Ergativity, Locality, Long Distance Agreement, Modern Indo-Aryan, Hindi-Urdu, Kashmiri, Restructuring

\begin{abstract}
Abbreviations: Abs - Absolutive; Acc - Accusative; Dat - Dative; Erg - Ergative; Neg - Negation; Prs Present; LDA - Long Distance Agreement; Hon - Honorific; D - Default; PSTPRT - Past Participle; NMLZ - Nominalizer; Pass - Passive Auxiliary; PSI - Polarity Sensitive Item; Inf - Infinitive; Pst - Past; Pfv Perfective; Impfv - Imperfective; Prog - Progressive; Hab - Habitual; Ger - Gerund; Obl - Oblique; 1 - 1st Person; 2 - 2nd Person; 3 - 3rd Person; F - Feminine; M - Masculine; N - Neuter; Sg - Singular; Pl - Plural;
\end{abstract}

\footnotetext{
* I would like to thank the reviewers of this paper and the editor Marcel den Dikken, whose comments have been very helpful. For questions and discussion I am indebted to Miriam Butt, Sandy Chung, David Embick, Sabine Iatridou, Luis López, Emily Manetta, Jim McCloskey, Line Mikkelsen, Roumyana Pancheva, Chris Potts, Joey Sabbagh, Bernhard Schwarz, Steve Wechsler, Anthony Woodbury, participants of the Spring 2003 Indo-Aryan syntax seminar at MIT and the Spring 2004 Indo-Aryan syntax seminar at UT Austin, and audiences at the SALA 21 in Konstanz, The University of Delhi, University of California, Santa Cruz,
} 


\section{Overview}

This paper provides a new analysis of the phenomenon of Long Distance Agreement in Hindi-Urdu that covers more empirical ground than existing analyses and reveals new generalizations. The phenomenon of Long Distance Agreement involves a verb agreeing with a constituent inside the verb's clausal complement and therefore poses a challenge to theories that assume that a strictly-local relationship such as the specifier-head relationship is necessary for agreement. The proposal argues for a less local conception of the agreement relationship that is nevertheless subject to locality considerations. It is thus in line with other recent proposals such as Benmamoun (1992), Bobaljik (1995), van Gelderen (1992), Chung (1998), Chomsky (1998, 1999, 2001), and Polinsky and Potsdam (2001).

To account for this phenomenon in Hindi-Urdu, the operation AGREE is invoked.

(1) AGREE is the process by which a head $X^{0}$ (the Probe) with a complete set of unvalued uninterpretable features identifies the closest $\mathrm{Y}^{0} / \mathrm{YP}$ in its c-command domain with the relevant set of visible matching (i.e. nondistinct) interpretable features (the Goal), and uses the interpretable features of $\mathrm{Y}^{0} / \mathrm{YP}$ to value its uninterpretable features.

This operation is similar in many respects to the operation Agree introduced in Chomsky (1998). The two operations differ in that Agree requires that Goals be active, i.e. have unvalued features, while AGREE does not place any such requirements. It is shown that a principle like AGREE (and not Agree) is needed to derive the facts of Long Distance Agreement in Hindi-Urdu as well as in Tsez (Polinsky and Potsdam (2001)).

and Northwestern University. Special thanks are due to Jonathan Bobaljik, Alice Davison, Veneeta Dayal, Ashwini Deo, Robert Frank and Andrew Nevins for giving me written comments. 
The following is a brief summary of the paper and a guide to its structure. $\S 2$ introduces the phenomenon and discusses Mahajan's (1989) analysis of it. Mahajan's (1989) proposal is argued to rest on problematic assumptions concerning case-licensing and a new proposal using AGREE is introduced in $\S 3$. The central idea behind this proposal is that a head can agree with an XP that it does not case-license. Finite $\mathrm{T}^{0}$ does not license the case of an object, but can enter into an AGREE relationship with it if the $\phi$-features of the subject are not visible and there is not a more local XP with visible $\phi$-features. Local object agreement and Long distance agreement are shown to involve the same structural configuration, the only difference being that of the distance between $\mathrm{T}^{0}$ and the element it enters into AGREE with. $\S 4$ identifies the environments where Long Distance Agreement is possible as involving restructuring. It is shown that certain environments where restructuring is not possible (e.g. subject infinitivals, gerunds, finite clauses) do not display Long Distance Agreement. $\S 5$ examines how the current proposal extends to some other languages with Long Distance Agreement, in particular Kashmiri, a dialect of Hindi-Urdu, and Tsez. The optionality of Long Distance Agreement is addressed in $\S 6$ and is related to the optionality in restructuring. Providing support for this relationship is the fact that environments where restructuring is obligatory display obligatory Long Distance Agreement. $\S 7$ concludes the paper by indicating further lines of inquiry and suggesting an assimilation between the operation AGREE proposed in this paper and the operation Agree introduced in Chomsky (1998). This assimilation which associates the activity condition on Goals with Move and not Agree retains the additional empirical ground captured by relaxing the condition on active Goals while at the same time not generating the cases of illegitimate raising that motivated the condition on active goals in the first place. 
Bhatt

\section{The Phenomenon of Long Distance Agreement}

\subsection{THE BASICS OF AGREEMENT IN HINDI-URDU}

The main verb (in participial form) and the auxiliary (if any) in Hindi-Urdu agree with the structurally most prominent argument of the verb that is not case-marked overtly. ${ }^{1}$ An argument is non-overtly case-marked if it is not marked with an overt case-clitic. This is exemplified in (2).

(2) a. Nominative subject, Accusative object, both non-overtly case-marked

\section{Rahul kitaab parh-taa thaa}

Rahul.M book.F read-Hab.MSg be.Pst.MSg

'Rahul used to read (a/the) book.'

b. Ergative subject, Accusative object, only object is non-overtly case-marked

\section{Rahul-ne kitaab parh-ii thii Rahul-Erg book.F read-Pfv.F be.Pst.FSg \\ 'Rahul had read the book.'}

In (2a), the subject and the object are both non overtly case-marked and so the participial verb and the auxiliary both agree with the subject, which is structurally the most prominent non-overtly case-marked argument. In (2b), the subject is overtly case-marked. Now the object is the structurally most prominent non-overtly case-marked argument and the participial verb and the auxiliary agree with it and not the overtly case-marked subject. When all arguments are overtly case-marked as in (3), the participial verb and the auxiliary display default agreement which corresponds to the features [3MSg].

(3) Ergative Subject, Overtly marked accusative object

Rahul-ne kitaab-ko parh-aa thaa Rahul-Erg book-Acc read-Pfv.MSg be.Pst.MSg

1 Participles and the past tense auxiliary agree in gender and number, the present tense auxiliary and the subjunctive agrees in number and person, and the future agrees in person, gender, and number. 
'Rahul had read the book.'

\subsection{LONG Distance Agreement}

Long Distance Agreement (LDA) refers to the phenomenon of a verb agreeing with an argument that is not its own. (4) exemplifies LDA. The matrix verb chaah 'want' agrees with kitaab 'book', which is not an argument of chaah 'want'.

(4) Vivek-ne [kitaab parh-nii] chaah-ii

Vivek-Erg book.F read-Inf.F want-Pfv.FSg

'Vivek wanted to read the book.'

chaah 'want' in (4) does not agree with its subject. This is not surprising given that its subject Vivek is overtly case-marked. In fact, LDA can only take place if the matrix verb has no non-overtly case-marked arguments of its own. However, chaah 'want' does agree with the object of its complement clause. This is surprising given the description of agreement in the previous section.

LDA has several properties two of which are briefly outlined in the following discussion. The remaining properties will be introduced along with the analysis.

\subsubsection{Optionality}

It has been noted by several authors that LDA in environments like (5) is optional (Hook (1979), Davison (1988), Mahajan (1989), Butt (1995)).

(5) (from Mahajan 1989)

a. LDA:

Ram-ne [rotii khaa-nii] chaah-ii

Ram-Erg bread.F eat-Inf.F want-Pfv.FSg

'Ram wanted to eat bread.'

b. no LDA: 
Ram-ne [rotii khaa-naa] chaah-aa Ram-Erg bread.F eat-Inf.M want-Pfv.MSg

'Ram wanted to eat bread.'

The authors who note the optionality of LDA have noted that the LD-agreeing object in (5a) seems more 'specific' than the non-agreeing object in (5b).

\subsubsection{Parasitic Agreement}

The infinitival verb agrees with its object only when there is LDA.

(6) a. LDA + infinitival agreement:

Shahrukh-ne [tehnii kaat-nii] chaah-ii thii

Shahrukh-Erg branch.F cut-Inf.F want-Pfv.F be.Pst.FSg

'Shahrukh had wanted to cut the branch.'

b. infinitival agreement but no LDA:

*Shahrukh-ne [tehnii kaat-nii] chaah-aa thaa Shahrukh-Erg branch.F cut-Inf.F want-Pfv.MSg be.Pst.MSg

'Shahrukh wanted to cut the branch.'

c. LDA but no infinitival agreement:

*Shahrukh-ne [tehnii kaat-naa] chaah-ii thii

Shahrukh-Erg branch.F cut-Inf.M want-Pfv.F be.Pst.FSg

'Shahrukh wanted to cut the branch.'

d. no infinitival agreement, no LDA:

Shahrukh-ne [tehnii kaat-naa] chaah-aa thaa Shahrukh-Erg branch.F cut-Inf.M want-Pfv.MSg be.Pst.MSg

'Shahrukh wanted to cut a/the branch.'

We know that LDA is only possible if the matrix verb has no non-overtly case-marked arguments of its own. Therefore when the matrix verb has a nominative subject, LDA is not possible. In these cases infinitival agreement is also not possible.

(7) a. no LDA and no infinitival agreement: 
Long Distance Agreement in Hindi-Urdu

Shahrukh [tehnii kaat-naa] chaah-taa thaa

Shahrukh branch.F cut-Inf.M want-Pfv.MSg be.Pst.MSg

'Shahrukh wants to cut the branch.'

b. infinitival agreement but no LDA:

*Shahrukh [tehnii kaat-nii] chaah-taa thaa

Shahrukh branch.F cut-Inf.F want-Pfv.MSg be.Pst.MSg

c. LDA but no infinitival agreement:

*Shahrukh [tehnii kaat-naa] chaah-tii thii

Shahrukh branch.F cut-Inf.M want-Pfv.FSg be.Pst.MSg

d. LDA and infinitival agreement:

*Shahrukh [tehnii kaat-nii] chaah-tii thii

Shahrukh branch.F cut-Inf.F want-Pfv.FSg be.Pst.MSg

It can be concluded from the discussion in this section that infinitival agreement is parasitic on LDA. Further when LDA takes place, Infinitival Agreement must take place.

\subsection{One Previous Analysis of Hindi-Urdu lDA: Mahajan (1989)}

\subsubsection{The Basic Analysis}

The central idea behind Mahajan's analysis of agreement in Hindi-Urdu is that the perfective participle, the imperfective/habitual participle, and the infinitival verb differ in their ability to assign accusative case. For Mahajan, perfective participles can never assign case to their objects. Imperfective participles always assign case to their objects. Finally infinitival verbs optionally assign case to their objects. Of course, the above three-way distinction is relevant only for transitive verbs. Unergative intransitives do not have objects, and unaccusatives do not assign case to their objects period.

Since for Mahajan (1989), perfective participles cannot assign case, something else must assign case to the objects of transitive perfective participles. This something else is an $\mathrm{Agr}^{0}$ head in association with finite tense. 
(8) a. [IPSugato-ne ${ }_{1}\left[{ }_{A g r P}\right.$ kitaab $\left._{2}\left[V_{P} \mathrm{t}_{1} \mathrm{t}_{2} \mathrm{t}_{v}\right] \mathrm{t}_{\text {agr }}\right]$ parhh-ii]

Sugato-Erg book.F read-Pfv.FSg

'Sugato read the book.'

Object agreement in (8) is for Mahajan a reflex of case-assignment by $\mathrm{Agr}^{0}$. He assumes that the imperfective participle assigns case to its object in situ. The object does not move to [Spec,AgrP] for case.
a. [IPSugato
${ }_{A g r P} \mathrm{t}_{1}\left[V_{P} \mathrm{t}_{1}\right.$ kitaab
hai] Sugato parh-taa read-Hab.MSg be.Prs.3Sg
'Sugato reads the book.'

Hence there is no object agreement with imperfective participles. The reader will note that (8) and (9) are not minimal pairs. With (most) transitive verbs, the switch from a perfective participle to an imperfective/habitual participle is accompanied by a change in the case assigned to the subject. This is why (8) involves an ergative subject and (9) involves a nominative subject.

Now let us examine how Long Distance Agreement takes place in Mahajan's system. Mahajan assumes that transitive infinitival verbs only optionally assign accusative case. When the infinitival verb does not assign accusative to its object, the object raises to the next highest case position, which happens to be the [Spec,AgrP] of the matrix verb. On its way to the matrix [Spec,AgrP], the embedded object passes through the [Spec,AgrP] of the embedded clause. This is why the embedded object agrees with both the infinitival verb and the matrix verb (cf. 10a). ${ }^{2}$
a. infinitival verb does not assign case $\rightarrow$ LDA

\footnotetext{
2 Mahajan assumes that the PRO subject of the embedded clause does not block the object of the embedded clause from moving over it to the matrix [Spec,AgrP]. We will see that in one form or another, all analyses of LDA in Hindi-Urdu have to make a similar assumption.
} 
Long Distance Agreement in Hindi-Urdu

[IP Sugato-ne $\left[{ }_{A g r P} \operatorname{rotii}_{i} \quad\left[{ }_{V P}\left[{ }_{I P} \mathrm{PRO}_{j}\left[\left[_{A g r P}\left[\mathrm{t}_{i}\left[\left[V_{V P} \mathrm{t}_{j} \mathrm{t}_{i} \mathrm{t}_{V 1}\right]\right.\right.\right.\right.\right.\right.\right.$

Sugato-Erg bread.F

khaanii $\left.\left.\left.\left.\left.{ }_{1}\right]\right]\right]\right]\right] \mathrm{t}_{V 2}$ ] $\mathrm{t}_{\text {agr } 2}$ ]] chaahii ${ }_{2}$ ]

eat-Inf.F

want-Pfv.FSg

'Sugato wanted to eat bread.'

b. infinitival verb assigns case $\rightarrow$ no LDA

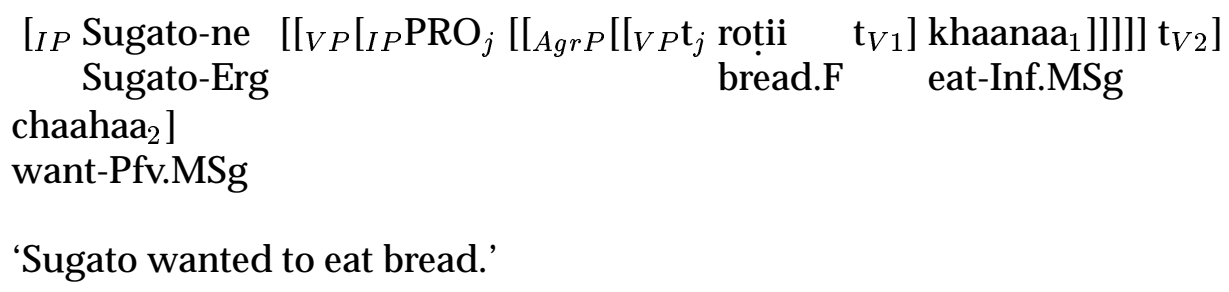

The optionality of LDA follows from the ability of the infinitival verb to optionally assign case (cf. 10b). When the infinitival verb assigns case, the object stays in-situ and there is no agreement, long or short distance. Note that the object never gets case from the embedded [Spec,AgrP] because $\mathrm{Agr}^{0}$ heads for Mahajan only assign case in association with finite tense.

\subsubsection{Some Problems}

Mahajan's analysis of LDA is quite promising. In particular, the properties of LDA noted in the introduction fall out without additional stipulations from Mahajan's analysis. However, it suffers from certain conceptual as well as empirical problems. The primary conceptual problem with Mahajan's analysis lies with his assumptions about the case-assigning properties of participles and non-finite verbs. The object case licensing properties of a verb are generally taken to be part of its argument structure. Accusative case is often related to transitive $v$, the head that licenses the external argument. Under most assumptions, this head is located below the level where Aspectual/Infinitival morphology is introduced. 
Given this architecture, we expect the case-assigning ability of a verb to be independent of whether it is part of a past participle, a present participle, or an infinitive, as also noted by Butt (1995). Case-assignment in Hindi-Urdu is dependent upon aspect but only the assignment of case to the subject. Case-licensing of objects is independent of the syntactic environment above the $v P .^{3}$

With the exception of the agreement facts which Mahajan explains using his assumption about the case-assigning properties of participles and infinitives, there does not seem to be empirical evidence on the basis of which the proposed difference between the caseassigning properties of perfective participles, imperfective participles, and infinitives can be justified. Transitive verbs seem to take accusative objects in a uniform fashion irrespective of the larger structure they are embedded in.

a. Infinitival:

[phal khaa-naa] sehat ke-liye achchhaa ho-taa hai fruit.Acc eat-Inf health for good be-Hab be.Prs.3Sg

'Eating fruits is good for health.'

b. Past Participle:

Mala-ne phal khaa-ye the Mala-Erg fruit.Acc eat-Pfv.MPl be.Pst.MPl

'Mala had eaten the fruits.'

c. Imperfective/Habitual Participle:

Mala phal khaa-tii hai Mala fruit.Acc eat-Hab.F be.Prs.3Sg

'Mala eats fruit.'

3 Mahajan's proposal transposed to English would amount to the proposal that eaten in John has eaten the apple does not assign accusative to its object, eating in John is eating the apple assigns case to its object, and eat in John wants to eat the apple only optionally assigns case to its object. This is similar to proposals such as Hoekstra (1994), where have re-transitivizes the past participle. 
Long Distance Agreement in Hindi-Urdu

While the above examples do not contradict Mahajan's proposal, they also do not provide support to it. The null hypothesis is that the case-assigning property of the verb is not affected by the location of the vP.

Evidence against the claim that perfective participles do not assign case to their objects comes from the fact that perfective participles embedded in infinitivals allow for overt objects.

(13) a. [Lataa-ji-kaa yeh gaanaa gaa-yaa ho-naa] namumkin hai Lataa-Hon-Gen this song sing-Pfv be-Inf impossible be.Prs.3Sg

'Lataa-ji's having sung this song is impossible.'

b. [Ashaa-ji-kaa yeh gaanaa gaa-yaa ho-naa] [Lataa-ji-ke Ashaa-Hon-Gen this song sing-Pfv be-Inf Lataa-Hon-Gen.Obl yeh gaanaa gaa-ye ho-ne]-se zyaadaa mumkin Lataa-Hon-Gen.Obl this song sing-Pfv.Obl be-Inf.Obl-Instr more hai possible be.Prs.3Sg

'Ashaa-ji's having sung this song is more likely than Lataa-ji's having sung this song.'

In $(13 a, b)$, it is not plausible that the object case is licensed by matrix tense. The infinitival tense cannot license object case, which must therefore be licensed by the perfective participle. There is also evidence against the claim that infinitival verbs can optionally not assign case, which will be introduced in the discussion of restructuring in $\S 4$.2.2.

Mahajan assumes that the embedded object overtly moves into the matrix [Spec,AgrP]. Based on examples like (14), Davison (1991) argues that the embedded object does not need to move out of the embedded clause to trigger Long Distance Agreement.

(14) (from Davison (1991))

mujhe zaruur $\mathrm{t}_{i}$ aa-tii hai [saikil chalaa-nii] $]_{i}$ me.Dat definitely come-Hab.F be.Prs.3Sg cycle ride-Inf.F

'I certainly know how to ride a bicycle.' 
Overt movement of the embedded object out of the infinitival clause would destroy the constituency of the infinitival verb and the embedded object and therefore predict incorrectly that (14) is ungrammatical. A similar point can be made through adverbial placement. In (15), the embedded trigger for LDA follows an adverb that modifies the embedded clause.

(15) Rohan-ne aaj [phir-se mehnat kar-nii] chaah-ii

Rohan-Erg today again hardwork.F do-Inf.F want-Pfv.FSg

'Today Rohan wanted to work hard again.'

The word order facts suggest that the LDA trigger is in the embedded clause. Therefore we can conclude that overt movement of the LDA trigger out of the embedded clause is not required for LDA.

Another empirical problem arises with respect to the non-licensing of subject case. Given that according to Mahajan's proposal, the case of the object of the infinitival complement is licensed by the matrix verb, we expect it to be possible for the subject of the embedded clause to also get case-licensed by matrix tense. As Mahajan himself points out, this is not the case.

\section{*Ram-ne [Mohan jaa-naa] chaah-aa} Ram-Erg Mohan go-Inf want-Pfv

In (16), the embedded predicate jaa 'go' does not assign case to its subject Mohan. Firstly jaa 'go' is an unaccusative and cannot assign case in principle and secondly even if it could assign case, it would be assigning case to its object and not its subject. Therefore without further stipulation, it should be the case that Mohan is able to move to the higher clause and get case-licensed there (and therefore trigger LDA). As the ungrammaticality of (16) shows, this is not the case. 
Long Distance Agreement in Hindi-Urdu

\section{Handling Long Distance Agreement}

\subsection{THE BASIC Proposal}

My proposal differs from earlier analyses of Long Distance Agreement in dissociating Case and Agreement. Within this proposal, heads enter into agreement relationships with elements that they do not case-license.

I assume that case assignment takes place in the way suggested by conventional theories of Case. For concreteness, I assume the following picture for transitive verbs: $v$, associated with transitive verbs, assigns Accusative to objects. Ergative case is assigned by Tense in association with transitive $v$ and Perfective Aspect. Other combinations of finite Tense, $v$, and Aspect lead to assignment of Nominative to the subject. Once we go beyond transitive verbs, the picture is much more complex. See Butt and King (2004) and Davison (2004) for proposals that attempt to capture the diversity of Hindi-Urdu case-assignment. Next we come to Agreement. Agreement within the clausal system is triggered by finite $\mathrm{T}^{0}$ with associated unvalued $\phi$-features. The operation involved in deriving Hindi-Urdu agreement is similar in many ways to the operation Agree developed in Chomsky (1998, $1999,2001)$ but there are also crucial differences between the two. In the discussion that follows I will introduce and motivate the properties of the operation that will be used to handle the Hindi-Urdu agreement system. This operation will be referred to as AGREE.

(17) AGREE is the process by which a head $X^{0}$ with unvalued uninterpretable features (the Probe) identifies the closest $\mathrm{Y}^{0} / \mathrm{YP}$ in its c-command domain with the relevant set of visible matching (i.e. nondistinct) interpretable features (the Goal), and uses the interpretable features of $\mathrm{Y}^{0} / \mathrm{YP}$ to value its uninterpretable features. (If the Probe is $\phi$-complete and the Goal has unvalued uninterpretable features, the Probe values and deletes these features.) 
In $\S 7.2$, the divergences between AGREE and Agree will be brought out and an assimilation of the two will be presented.

Using AGREE, finite $\mathrm{T}^{0}$ identifies the nearest argument with visible $\phi$-features and uses them to value its $\phi$-features. In (18a), the nearest visible $\phi$-features are those of the subject and finite $\mathrm{T}^{0}$ uses them to value its unvalued $\phi$-features resulting in subject agreement. The subject in (18b) is overtly case-marked and as a result of a Hindi-Urdu specific restriction, ${ }^{4}$ its $\phi$-features are not visible. The closest visible $\phi$-features now belong to the object and therefore finite $\mathrm{T}^{0}$ uses them to value its $\phi$-features resulting in object agreement. Finally if there are no visible $\phi$-features in the domain as in (18c), the unvalued $\phi$-features of $\mathrm{T}^{0}$ receive a default realization i.e. [3MSg].

a. subject agreement:

Mona amruud khaa-tii thii

Mona.F guava.F eat-Hab.F be.Pst.FSg

'Mona used to eat guavas.'

b. object agreement:

Ram-ne imlii khaa-yii thii

Ram.M-Erg tamarind.F eat-Pfv.F be.Pst.FSg

'Ram had eaten tamarind.'

c. default agreement:

Mona-ne is kitaab-ko parh-aa thaa

Mona.F-Erg this.Obl book.F-Acc read-Pfv.MSg be.Pst.MSg

'Mona had read this book.'

The above discussion is able to derive the agreement on $\mathrm{T}^{0}$. But as $(18 \mathrm{a}, \mathrm{b})$ show, participles also agree with whatever $\mathrm{T}^{0}$ is agreeing with. There are two options available here. The first option assumes that only $\phi$-complete $\mathrm{T}^{0}$ (i.e. finite $\mathrm{T}^{0}$ ) can function as a Probe in Hindi-Urdu. $\mathrm{T}^{0}$ tries to locate an element with $\phi$-features. The closest head which has

\footnotetext{
4 The nature of this restriction and its crosslinguistic distribution are discussed in §3.2.2.
} 
a putative $\phi$-feature specification is the participial head Asp, which could be habitual or perfective (cf. 19). ${ }^{5}$

a. $\mathrm{T}^{0}[\mathrm{uF}] \ldots .\left[\operatorname{Asp}^{0}[\mathrm{uF}] \ldots .\left[{ }_{v P} \mathrm{SUBJ}[\phi \mathrm{F}] v\left[{ }_{V P} \mathrm{~V} \mathrm{OBJ}[\phi \mathrm{F}]\right]\right]\right]$

$$
\text { (Asp = Habitual) }
$$

b. $\mathrm{T}^{0}[\mathrm{uF}] \ldots\left[\operatorname{Asp}^{0}[\mathrm{uF}] \ldots .\left[{ }_{v P} \mathrm{SUBJ}-\mathrm{Erg} v\left[{ }_{v P} \mathrm{~V}\right.\right.\right.$ OBJ $\left.\left.\left.[\phi \mathrm{F}]\right]\right]\right]$

$$
\text { (Asp }=\text { Perfective, } v \text { transitive) }
$$

However, the participial head does not have interpretable features of its own. At this point, the features of $\mathrm{T}^{0}$ and the participial head are not valued but a dependency is created between them. Since the features of $\mathrm{T}^{0}$ have not been valued, it looks further. In (18a), it locates the subject and uses its features to value its unvalued $\phi$-features and to covaluate the participle's unvalued $\phi$-features (cf. 19a). In (18b), the subject is overtly case-marked and hence its $\phi$-features are invisible (cf. 19b). $\mathrm{T}^{0}$ therefore locates the object and both the $\mathrm{T}^{0}$ and the participle come to agree with the object. Participial agreement is now parasitic on $\mathrm{T}^{0}$ and when $\mathrm{T}^{0}$ does not locate an argument with visible $\phi$-features as in (18c), both $\mathrm{T}^{0}$ and the participle display default agreement. We can refer to the process by which the unvalued $\phi$-features of the participial head are valued as covaluation. In particular, we can say that $\mathrm{T}^{0}$ covaluates the participial head.

The second option allows for both $\mathrm{Asp}^{0}$ and finite $\mathrm{T}^{0}$ to serve as Probes. They both identify the same Goal (the object) and use its interpretable $\phi$-features to value their own $\phi$-features. Asp ${ }^{0}$ is not $\phi$-complete and hence does not block an AGREE relationship between $\mathrm{T}^{0}$ and the object. This option seems considerably simpler than the first. In particular, we do not need to specify the list of potential probes. Anything with uninterpretable features qualifies. However, the parasitic nature of Hindi-Urdu LDA suggests that the first option is what seems to be in order.

\footnotetext{
${ }^{5}$ The various heads in (19) are shown as head-initial merely to aid the exposition. Their actual directionality is irrelevant for the structural point being made here.
} 
Long Distance Agreement does not require any special treatment. If we assume following the first option that finite $\mathrm{T}^{0}$ is the only probe (and not $\operatorname{Inf}^{0}$ ), the closest visible set of $\phi$-features in (20) belong to the embedded object. Therefore the matrix $\mathrm{T}^{0}$ uses the embedded object's $\phi$-features to value its $\phi$-features.

\section{(20)}

\section{Ram-ne [rotii khaa-nii] chaah-ii thii Ram-Erg bread.F eat-Inf.F want-Pfv.F be.Pst.FSg \\ 'Ram had wanted to eat (the) bread.'}

Like participial agreement in (18), infinitival agreement is also covaluated by $\mathrm{T}^{0}$. Matrix $\mathrm{T}^{0}$ first enters into a relationship with the infinitival head $\operatorname{Inf}^{0}$ because $\operatorname{Inf}^{0}$ is the closest head with visible though unvalued $\phi$ features (cf. 21).

$$
\mathrm{T}^{0}[\mathrm{uF}]\left[\text { Subj-Erg } \mathrm{V}^{0}\left[\operatorname{Inf}^{0}[\mathrm{uF}] \ldots . \mathrm{OBJ}[\phi \mathrm{F}]\right]\right]
$$

Then when it finds an argument with visible and interpretable $\phi$-features, it uses those features to value its own unvalued features and covaluate the $\phi$-features of the infinitival head. Alternatively, if both $\operatorname{Inf}^{0}$ and finite $\mathrm{T}^{0}$ function as probes, they both independently use the features of the object to value their features. As in (18), $\operatorname{Inf}^{0}$ does not constitute an intervener for the AGREE relationship between finite $\mathrm{T}^{0}$ and the object because $\operatorname{Inf}^{0}$ is not $\phi$-complete.

The proposal as it stands is able to explain the paradigm in (22).

a. LDA but no infinitival agreement:

*Ram-ne [rotii khaa-naa] chaah-ii thii Ram-Erg bread.F eat-Inf.MSg want-Pfv.F be.Pst.FSg

'Ram had wanted to eat (the) bread.'

b. infinitival agreement but no LDA:

*Ram-ne [rotii khaa-nii] chaah-aa thaa Ram-Erg bread.F eat-Inf.F want-Pfv.MSg be.Pst.MSg

'Ram had wanted to eat (the) bread.' 
Under the assumption that only finite $\mathrm{T}^{0}$ functions as a Probe, the ungrammaticality of $(22 \mathrm{a}, \mathrm{b})$ receives a common explanation. Inf $^{0}$ cannot value its uninterpretable features by itself. Only finite $\mathrm{T}^{0}$ can do this. So for $\mathrm{Inf}^{0}{ }^{\prime} \mathrm{s}$ uninterpretable features to be covaluated, $\mathrm{T}^{0}$ uninterpretable features must also get valued and to value its own features, $\mathrm{T}^{0}$ must covaluate the features of the intervening $\operatorname{Inf}^{0}$. One cannot happen without the other. The facts of (22) also follow if both $\operatorname{Inf}^{0}$ and finite $\mathrm{T}^{0}$ are Probes - they both locate the same Goal and independently enter into AGREE with it. Given the structure of $(22 a, b)$, if $\operatorname{Inf}^{0}$ locates a Goal, then $\mathrm{T}^{0}$ will also locate the same Goal and vice versa.

The choice between the two options - (i) finite $\mathrm{T}^{0}$ as the only Probe and (ii) both finite $\mathrm{T}^{0}$ and $\operatorname{Inf}^{0}$ are Probes - is made by the facts concerning the parasitic nature of LDA. These facts show that the infinitival verb cannot agree with the embedded object if the embedded object does not agree with the matrix finite $\mathrm{T}^{0}$. In the structures in (23), the matrix $\mathrm{T}^{0}$ identifies the matrix subject as its Goal and does not enter into an AGREE relationship with the embedded object. LDA is therefore not an option, yielding the ungrammaticality of $(23 c, d)$. The ungrammaticality of $(23 b)$ is more puzzling.

a. no LDA and no infinitival agreement:

Shahrukh [tehnii kaat-naa] chaah-taa thaa Shahrukh branch.F cut-Inf.M want-Hab.MSg be.Pst.MSg

'Shahrukh wants to cut the branch.'

b. infinitival agreement but no LDA:

*Shahrukh [tehnii kaat-nii] chaah-taa thaa Shahrukh branch.F cut-Inf.F want-Hab.MSg be.Pst.MSg

c. LDA but no infinitival agreement:

*Shahrukh [tehnii kaat-naa] chaah-tii thii Shahrukh branch.F cut-Inf.M want-Hab.FSg be.Pst.FSg

d. LDA and infinitival agreement:

*Shahrukh [tehnii kaat-nii] chaah-tii thii

Shahrukh branch.F cut-Inf.F want-Hab.FSg be.Pst.FSg 
If both $\operatorname{Inf}^{0}$ and finite $\mathrm{T}^{0}$ were Probes, we would expect (23b) to be grammatical. $\operatorname{Inf}^{0}$ would identify the embedded object as its Goal and enter into AGREE with it and the matrix finite $\mathrm{T}^{0}$ would enter into AGREE with the matrix subject. Since (23b) is not in fact grammatical, I take it that $\operatorname{Inf}^{0}$ cannot be a Probe by itself. The ungrammaticality of $(23 b)$ follows if $\mathrm{T}^{0}$ is the only Probe. The features of $\operatorname{Inf}^{0}$ can be valued only by finite $\mathrm{T}^{0}$ and this happens only if $\mathrm{T}^{0}$ enters into an AGREE relationship with an element that crosses $\operatorname{Inf}^{0}$. Since this is not the case in (23), infinitival agreement is not possible.

It should be noted that the proposal for Long Distance Agreement is the same as the proposal made for local object agreement. This makes sense once we observe that similar structural relationships hold in both local object agreement and Long Distance Agreement. The finite $\mathrm{T}^{0}$ head is not directly related to the object that it agrees with. Finite $\mathrm{T}^{0}$ is involved in the licensing of nominative/ergative case on the subject while the case on the object is licensed by transitive $v$. This can be shown by the fact that object case is licensed even when the clause is non-finite (cf. 24).

$$
\begin{aligned}
& \text { [imlii khaa-naa] achchhaa hai } \\
& \text { tamarind.F eat-Inf good.Msg be.Prs.3Sg } \\
& \text { 'To eat tamarind is good.' }
\end{aligned}
$$

Further in the process of valuating its $\phi$-features using the $\phi$-features of the object, $\mathrm{T}^{0}$ also values the $\phi$-features of $\mathrm{Asp}^{0} / \operatorname{Inf}^{0}$. Thus the relationship between finite $\mathrm{T}^{0}$ and the DP it agrees with as well as the process by which the unvalued $\phi$-features of intervening heads are covaluated is the same in both (18b) and (20).

\subsection{BACKGROUND ASSUMPTIONS}




\subsubsection{Finiteness and $\phi$-Completeness}

In (18), finite $\mathrm{T}^{0}$ is overtly realized by a form of the auxiliary 'be'. Finite $\mathrm{T}^{0}$ is, however, not always overtly realized. Simple past tense sentences in Hindi-Urdu do not involve an overt expression of tense (cf. 25a). Further, negated present habitual sentences do not require overt expression of tense (cf. 25b).

a. Simple Past:

Ram-ne imlii khaa-yii

Ram.m-Erg tamarind.F eat-Pfv.FSg

'Ram ate tamarind.'

b. Negated Present Habitual:

Mona amruud nahĩ: khaa-tii (hai)

Mona.F guava.m Neg eat-Hab.F be.Prs.3Sg

'Mona does not eat guavas.'

Despite the absence of an overt tense bearing auxiliary in (25a), I assume that there is a covert $\mathrm{T}^{0}$ head in (25a). It is possible that the $\mathrm{V}+\mathrm{Asp}^{0}$ complex combines via stringvacuous movement with this head. The covert $\mathrm{T}^{0}$ head triggers agreement as discussed above. A similar $\mathrm{T}^{0}$ head is also postulated for $(25 \mathrm{~b})$ when there is no overt tense-bearing auxiliary. More generally I assume that any interrogative or declarative sentence that can appear by itself has a finite $\mathrm{T}^{0}$ head, which may or may not be realized overtly.

An important component of our analysis of Long Distance Agreement has been that Inf $^{0}$ does not constitute an intervener between the matrix finite $\mathrm{T}^{0}$ and the embedded object. This was related to $\operatorname{Inf}^{0}$ not being $\phi$-complete. The notion of $\phi$-completeness was introduced in Chomsky (1999) - finite/control $\mathrm{C}^{0} / \mathrm{T}^{0}$ is $\phi$-complete because it has person features, while raising/ECM $\mathrm{T}^{0}$ is not $\phi$-complete lacking person features. An anonymous reviewer points out that in Hindi-Urdu this straightforward correlation between morphological realization of features and $\phi$-completeness does not work fully (see also López (2002) for a discussion of the crosslinguistic manifestations of $\phi$-completeness). 
While it is true that no non-finite form $\left(\mathrm{Asp}^{0}, \operatorname{Inf}^{0}\right)$ displays person features, it is not the case that all finite forms display person agreement. For example the past tense auxiliary, being derived historically from a participial form, only agrees in number and gender and not in person. The present tense auxiliary agrees in person and number but not in gender. Only the future agrees in person, number, and gender. And yet, irrespective of what features they overtly realize all finite forms function as interveners for the purpose of LDA. I take this to show that finite $\mathrm{T}^{0}$ always has features for Person, Number, and Gender, i.e. it is $\phi$-complete. Whether these features are overtly realized or not depends upon the morphological properties of the auxiliary involved.

\subsubsection{Overt Case-Marking and the Visibility of $\phi$-features}

The current proposal needs to assume that the $\phi$-features of overtly case-marked NP's and the PRO subject of the embedded infinitival clause are not visible for the purposes of agreement. Existing analyses of LDA in Hindi-Urdu need to make comparable assumptions. In this section, I address the part of this assumption which concerns overtly case-marked NP's. The invisibility of PRO for the purposes of agreement is addressed in $\S 4.2 .2$ in the context of the discussion of restructuring, where it is proposed that the putative invisibility of PRO follows the non-projection of a PRO subject in infinitival clauses that permit LDA.

It is not known why overtly case-marked NP's in Hindi-Urdu do not agree, but this property of overtly case-marked NP's being invisible for agreement seems to be shared by several but not all ergative Indo-Aryan languages. Kashmiri, Marathi, and Punjabi pattern with Hindi-Urdu. But in Nepali, ergative subjects (which are overtly case-marked) agree, and in a manner parallel to nominative subjects.

(26) (Nepali, from Verma and Sharma (1979), pg. 47)

a. Ergative Subject: 
maile gaiko aaitvaar dhairai raksi: kha:ẽ

I-Erg gone Sunday a-lot alcohol eat-Pst.1Sg

'I drank a lot last Sunday.'

b. Nominative Subject:

ma asti somvaar sku:lma: dhi:lo a:ẽ

I-Nom last Monday school-in late come-Pst.1Sg

'I was late to school last Monday.'

In Gujarati, ergative subjects do not agree but overtly case-marked accusative objects agree (cf. Subbarao (2001)).

(27) (Gujarati, from Cardona (1965), pg. 75)

a. mEN tehmahri behEn-one bolawi

I-Erg your sisters-Acc invited.F

'I invited your sisters.'

b. pustek 'book' is Neuter

mEN a pustek-ne waNcyuN

I-Erg this book-Acc read.N

'I read this book.'

In both $(27 a, b)$, the verb does not agree with the Ergative subject. It does, however, agree with the overtly case-marked accusative object. Because of the variation in the effect of overt case-marking on agreement, Subbarao (2001) notes, and I concur, that the effect of overt case-marking on agreement should be treated as an instance of parametric variation and not as a universal. The Nepali facts demonstrate that languages differ with respect to whether the presence of overt case-marking blocks agreement. The Gujarati facts further reveal that even within a language, case-markers differ in whether they block agreement. Ergative case-marking in Gujarati blocks agreement but not accusative case-marking. See Comrie (1984) and Deo and Sharma (2002) for a discussion of the variation manifested within the Modern Indo-Aryan languages with respect to the relationship between overt case-marking on a DP and the visibility of that $\mathrm{XP}^{\prime}$ s agreement features. 


\subsection{DiRECTIONALITY}

When there is Long Distance Agreement, we find an embedded object agreeing with the matrix $\mathrm{T}^{0}$. However, the reverse process where the infinitival verb agrees with the matrix subject is not attested (cf. 28). ${ }^{6}$

(28) (from Mahajan 1989)

a. Infinitival verb shows default agreement:

Mona [kuttõ-ko dekh-naa] chaah-tii thii Mona.F dog.MPl-Acc see-Inf.M.Sg want-Hab.F be.Pst.FSg

'Mona wanted to see the dogs.'

b. Infinitival verb agrees with matrix subject:

*Mona [kuttõ-ko dekh-nii] chaah-tii thii Mona.F dog.MPl-Acc see-Inf.F.Sg want-Hab.F be.Pst.FSg

This feature of agreement follows from the way AGREE operates. To see why a structurally lower argument can agree with a higher head but a structurally higher argument cannot agree with a lower head, let us examine the structures involved in long distance agreement and in the unattested (28) that involves 'downward' agreement.

a. Long Distance Agreement:

Before AGREE: $\mathrm{T}^{0}[\mathrm{uF}] \ldots\left[\operatorname{Inf}^{0}[\mathrm{uF}] \ldots \mathrm{DP}[\phi \mathrm{F}]\right]$

After AGREE: $\mathrm{T}^{0}[\phi \mathrm{F}] \ldots\left[\operatorname{Inf}^{0}[\phi \mathrm{F}] \ldots \mathrm{DP}[\phi \mathrm{F}]\right]$

${ }^{6}$ The directionality facts provide a clear argument against a naive restructuring analysis of LDA. According to such an analysis, Long Distance Agreement would involve 'clause union' i.e. all the verbs would form a single unit which would together combine with the nominal arguments. But then given the agreement system of Hindi-Urdu, such an analysis would make the incorrect prediction that (28) is grammatical. This argument does not carry over to more sophisticated analyses of restructuring such as Wurmbrand (2001) which do not handle restructuring phenomena in terms of 'clause union'. 
b. 'Downward' Agreement:

Before AGREE: $\mathrm{T}^{0}[\mathrm{uF}] \ldots \mathrm{DP}[\phi \mathrm{F}] \ldots\left[\operatorname{Inf}^{0}[\mathrm{uF}] \ldots.\right]$

*After AGREE: $\mathrm{T}^{0}[\phi \mathrm{F}] \ldots \mathrm{DP}[\phi \mathrm{F}] \ldots\left[\operatorname{Inf}^{0}[\phi \mathrm{F}] \ldots . ..\right]$ (unattested)

In (29a), $\mathrm{T}^{0}$ seeks an appropriate element to value $\mathrm{T}^{0}$ 's unvalued features. The first element it finds is $\operatorname{Inf}^{0}$. This leads to $\mathrm{T}^{0}$ and $\operatorname{Inf}^{0}$ entering into a relationship, but since $\operatorname{Inf}^{0}$ does not have any interpretable features, the features of both stay unvalued. $\mathrm{T}^{0}$ looks further and finds the embedded DP object and enters into AGREE with it. It uses the DP's features to value its own features and covaluate the features of $\operatorname{Inf}^{0}$.

In (29b), $\mathrm{T}^{0}$ right away locates the matrix DP and enters into AGREE with it. Since its unvalued features are valued by the DP, it cannot look further. Therefore it does not enter into a relationship with the $\operatorname{Inf}^{0}$ and $\operatorname{Inf}^{0}$ cannot access the matrix DP's features via covaluation. In the system under discussion, $\operatorname{Inf}^{0}$ never participates in agreement by itself. But even if it could, it would not be able to agree with the matrix DP in (29b) because the matrix DP is not in $\operatorname{Inf}^{0}$ 's c-command domain and a head can only enter into an AGREE relationship with a DP in its c-command domain (cf. the definition of AGREE in 17).

\subsection{AgreEment nOt CASE}

The current analysis dissociates Case from Agreement. Therefore it does not predict spurious case-licensings. As discussed earlier, this was a problem for Mahajan (1989).

(30) *Ram-ne [Mohan jaa-naa] chaah-aa

Ram-Erg Mohan go-Inf want-Pfv

It was unclear under Mahajan's analysis why Mohan, the embedded subject, could not receive case from matrix tense while embedded objects could. This problem does not arise within the current proposal because matrix Tense is not involved in Case-licensing 
Bhatt

the arguments of the infinitival clause. Object case is licensed because of the infinitival verb and Mohan cannot surface as the subject of the infinitival because there is no source for case within the infinitival clause. If a source for case is provided, the sentence becomes grammatical.

(31) Ram-ne [Mohan-kaa jaa-naa] chaah-aa Ram-Erg Mohan-Gen go-Inf want-Pfv

'Ram wanted Mohan's leaving.'

\section{Long Distance Agreement Environments}

\subsection{No LDA out of Finite Clauses}

Long Distance Agreement can only involve arguments of infinitival clauses. It cannot attract the features of an embedded finite clause.

a. $\mathrm{T}^{0}[\mathrm{D}] \mathrm{A}-\mathrm{Erg} \mathrm{V}\left[\mathrm{C}^{0}\left[\mathrm{~T}^{0}[\mathrm{~B}] \mathrm{B} \ldots\right.\right.$

Firoz-ne soch-aa ki [Mona ghazal gaa-tii hai]

Firoz-Erg think-Pfv.MSg that Mona.F ghazal.F sing-Hab.F be.Prs.3Sg

'Firoz thought that Mona sings ghazals.'

b. ${ }^{*} \mathrm{~T}^{0}[\mathrm{~B}] \mathrm{A}-\mathrm{Erg} \mathrm{V}\left[\mathrm{C}^{0}\left[\mathrm{~T}^{0}[\mathrm{~B}] \mathrm{B} \ldots\right.\right.$

*Firoz-ne soch-ii ki [Mona ghazal gaa-tii hai] Firoz-Erg think-Pfv.FSg that Mona.F ghazal.F sing-Hab.F be.Prs.3Sg

The embedded clause is a finite CP and given that finite CPs constitute strong phases and the Phase Impenetrability Condition (PIC) of Chomsky (1999), the embedded finite $\mathrm{T}^{0}$ and other TP-internal material would be invisible to the matrix finite $\mathrm{T}^{0}$.

Due to the head-final nature of Hindi-Urdu and the unavailability of reliable adverbial markers, it is not clear whether the embedded subject resides in [Spec,TP] or in a lower position. If the embedded subject is in a lower position than [Spec,TP], then a Minimalitybased explanation that is independent of assumptions about phases becomes available. 
The matrix finite $\mathrm{T}^{0}$ cannot 'look past' another finite $\mathrm{T}^{0}$ while looking for an argument with visible interpretable $\phi$-features. Because of the minimality condition on AGREE, the matrix $\mathrm{T}^{0}$ in (32a) cannot attract the features of $\mathrm{B}$ over the intervening finite $\mathrm{T}^{0}$ in the embedded clause. However, we also need to explain why the matrix $\mathrm{T}^{0}$ cannot attract the features from the embedded $\mathrm{T}^{0}$. The explanation comes from the observation that a finite $\mathrm{T}^{0}$ with unvalued $\phi$-features can only AGREE with 'real' $\phi$-features, i.e. interpretable $\phi$ features associated with a nominal, and not the uninterpretable $\phi$-features of another inflectional head. The case in (32) differs from the case in (20). There, both the matrix verb and the infinitival verb agree with the embedded object. Note though that in (20), the matrix verb is not actually agreeing with the infinitival verb. It is agreeing with the embedded object and in the process is covaluating the intervening unvalued $\phi$-features of the infinitival verb.

\subsection{Restructuring And Long Distance Agreement}

It might appear from the preceding discussion that Long Distance Agreement is always possible out of infinitival clauses. This is, however, not the case.

a. [mehnat kar-naa $/{ }^{*}$ kar-nii] achchhaa $/{ }^{*}$ ii ho-taa $/{ }^{*}$ ii hai hardwork.F do-Inf.D do-Inf.F good.D/F be-Hab.D/F be.Prs.3Sg

'It is good to work hard.'

b. Anjum-ne Saddaf-ko [chițhii likh-ne]-ko kah-aa/*ii Anjum-Erg Saddaf-Dat letter.F write-Inf.Obl-Dat say-Pfv.MSg/F thaa / ${ }^{*}$ thii be.Pst.MSg/F

'Anjum told Saddaf to write a letter.'

Let us contrast the non-LDA environments in (33) with the LDA environments in (34).

a. mantri-ji-ne [saare samaachaar jaan-ne] chaah-e minister-Hon-Erg all.MPl news.MPl know-Inf.MPl want-Pfv.MPl the be.Pst.MPl 
'The minister had wanted to know all the news.'

b. Nadia-ko [gaarii chalaanii] aa-tii hai Nadia-Dat car.F drive-Inf.F come-Hab.F be.Prs.3Sg

'Nadia knows how to drive a car.'

c. Nadia-ne [Sarosh-ko gaarii chalaa-ne] di-i Nadia-Erg Sarosh-Acc car.F drive-Ger.Obl let-Pfv.FSg

'Nadia let Sarosh drive the car.'

An important difference between the environments in (34) and the environments in (33) is that the environments in (34), but not the environments in (33), involve complex predicate formation/restructuring.

\subsubsection{Identifying Restructuring}

The notion of restructuring has been discussed extensively for the Germanic and the Romance languages. Restructuring refers to a class of phenomena where certain ordinarily clause-bounded processes apply across the boundaries of infinitival clauses. The exact processes implicated seem to vary from language to language. Clitic Climbing is a signature property of restructuring in Romance languages. Clitic climbing is possible out of the complement of a restructuring verb (= a restructuring infinitive) but not out of the complement of a non-restructuring verb (cf. Aissen and Perlmutter (1976/1983), Rizzi (1976/1978) a.o.).

(35) (from Wurmbrand (1998:35))

a. want is a restructuring verb, Clitic Climbing

Gianni $\mathrm{lo}_{i}$ ha voluto [leggere $\mathrm{t}_{i}$ ]

Gianni it-CL has wanted to-read $\mathrm{t}_{C L}$

'Gianni wanted to read it.'

b. decide is not a restructuring verb, No Clitic Climbing

${ }^{*}$ Gianni $l_{i}$ ha deciso [leggere $t_{i}$ ] Gianni it-CL has decided to-read $t_{C L}$ 
'Gianni decided to read it.'

The corresponding property for the Germanic languages is Long Distance Scrambling. In general non-focus scrambling in German cannot cross clause boundaries. Scrambling is, however, possible out of the complements of restructuring verbs like try.

(36) (from Wurmbrand (2001:41))

a. try is a restructuring verb, Long Distance Scrambling

dass Hans [den Traktor $]_{i}$ versucht has $\left[\mathrm{t}_{i}\right.$ zu reparieren] that John the-Acc tractor tried had to repair

'that John (has) tried to repair the tractor'

b. plan is a non restructuring verb, No Long Distance Scrambling

\%dass Hans [den Traktor $]_{i}$ geplant hat $\left[\mathrm{t}_{i}\right.$ zu reparieren] that John the-Acc tractor planned has to repair 'that John (has) planned to repair the tractor.'

The verbs out of whose complements we find Long Distance Agreement in Hindi-Urdu want, let, know how - are restructuring predicates in many languages. want, in particular, is a prototypical restructuring predicate (Dutch, German, Italian, Spanish, Catalan a.o.). The status of let seems to vary crosslinguistically and sometimes even among different speakers of the same language. In a detailed study of restructuring/complex predicate phenomena in Hindi-Urdu, Butt (1995) shows convincingly that let in Hindi-Urdu involves restructuring. She also shows that $(33 b)$ does not involve restructuring (in her terms, complex predicate formation). The diagnostics she uses involve control, anaphora, and agreement. Unfortunately, out of these three diagnostics, only agreement is applicable to $(34 a, b) .^{7}$

\footnotetext{
${ }^{7}$ An anonymous reviewer points out that while all of (34a-c) might involve restructuring, this does not presuppose a common analysis and further notes that LDA with complements of the permissive de 'give, let' and LDA with complements of chaah 'want' and aa 'come, know how' differ in optionality. With the
} 
I introduce a new diagnostic based on the scope of negation in an embedded infinitival clause. Negation in a restructuring infinitive can take scope over the embedding verb. In other environments, the scope of negation is clause-bound. See Mahajan (1990b) for an analysis of these facts. To diagnose the scope of negation, a NPI will be placed in the subject position of the matrix clause. With a restructuring verb like want, we find that a negation embedded in the infinitival clause is able to license an NPI in the matrix subject position.

(37) Restructuring Infinitive: embedded negation licenses matrix NPI

ek-bhii larke-ne [Sita-kii kitaab nahĩ: paṛh-nii] chaah-ii one-PSI boy-Erg Sita-Gen.F book.F Neg read-Inf.F want-Pfv.FSg

'Not even a single boy wanted to read Sita's book.'

In contrast, a negation embedded in a non-restructuring infinitive is unable to license a matrix NPI.

a. *ek-bhii larke-ne Sita-se [kitaab nahĩ: paṛh-ne]-ko kah-aa one-PSI boy-Erg Sita-Inst book.F Neg go-Inf.Obl-Dat say-Pfv

b. ek-bhii larke-ne Sita-se [kitaab parh-ne]-ko nahĩ: kah-aa one-PSI boy-Erg Sita-Inst book.F go-Inf.Obl-Dat Neg say-Pfv

'Not even a single boy told Sita to read the book.'

The facts stay the same in (39) showing that we have a non-restructuring infinitive here. This is to be expected because the infinitival clause in question is in a subject position and restructuring is only an option for complement infinitival clauses.

a. [mehnat nahĩ: kar-naa] (*kabhii-bhii) achchhaa ho-taa hardwork.F Neg do-Inf.3MSg ever good.MSg be-Hab.MSg hai be.Prs.3Sg

former LDA is obligatory while with the latter it is optional. We will return to this issue when we address the optionality of LDA in $\S 6$. 
Long Distance Agreement in Hindi-Urdu

'To not work is (*ever) good.'

b. [mehnat kar-naa] (kabhii-bhii) achchhaa nahĩ: ho-taa hardwork.F do-Inf.3MSg ever good.MSg Neg be-Hab.MSg hai be.Prs.3Sg

'To work isn't (ever) good.'

The above demonstration supports the conclusion that Long Distance Agreement is restricted to restructuring infinitives.

\subsubsection{Towards an analysis of Restructuring}

Having established a correlation between Restructuring and Long Distance Agreement, we need to address the question of why this correlation exists. A range of approaches to restructuring share the property that they treat restructuring infinitives as being somehow reduced or deficient, as lacking some property that non-restructuring infinitives have. The intuition is that it is this property that blocks Long Distance Agreement. To make this intuition precise, we need to adopt a particular analysis of restructuring. I will adopt a modified version of Wurmbrand's (2001) treatment of restructuring infinitives. The central idea behind Wurmbrand's (2001) proposal is that restructuring infinitives are reduced structures which do not involve projection of an embedded subject.

$$
\text { [Subject [v [VP } \mathrm{V}_{R V}[\text { InfinitivalVP } \mathrm{V} \text { OBJ]]]] }
$$

In addition, Wurmbrand (2001) argues that in German, Japanese, Italian and Spanish, there is no source for the licensing of accusative case within the restructuring infinitive. The case-licensor for the embedded object is external to the restructuring infinitive. In (40), the case on the embedded OBJ would be licensed by the $v$ associated with the matrix clause. Wurmbrand's proposal is motivated by the facts associated with 'Long Passive' in German. 
a. Restructuring Infinitive: (from Wurmbrand (2001:19))

dass der Traktor zu reparieren versucht wurde that the-Nom tractor to repair tried was 'that they tried to repair the tractor.'

b. Nonrestructuring Infinitive: (from Wurmbrand (2001:36))

*dass der Traktor zu reparieren geplant wurde that the-Nom tractor to repair planned was 'that they planned to repair the tractor.'

Under Wurmbrand's (2001) proposal, the facts of the 'Long Passive' follow straightforwardly and the construction is assimilated to the regular passive. Once the matrix clause is passivized, in consonance with Burzio's Generalization, the matrix $v$ can no longer license accusative case on the embedded object. The embedded object needs to find its case-licensor higher in the tree. In (41a), the licensor is finite $\mathrm{T}^{0}$ and the embedded object appears in the nominative.

I adopt Wurmbrand's (2001) proposal for restructuring but with a principled difference in that I allow for restructuring infinitives in Hindi-Urdu to license accusative case. The deviation from Wurmbrand's (2001) proposal is a principled one because Hindi-Urdu is a well-known exception to Burzio's Generalization (see Mahajan (1995) a.o.). Passivization does not block licensing of accusative case in Hindi-Urdu.

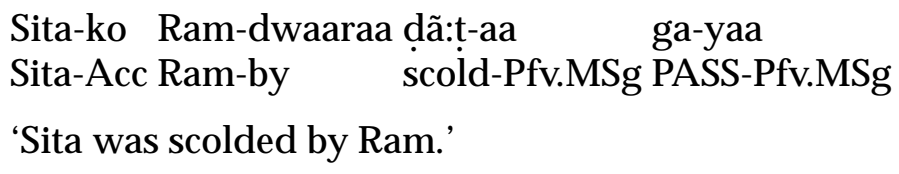

In addition the facts involving 'Long Passive' that motivated the case-licensing component of Wurmbrand's (2001) analysis do not obtain in Hindi-Urdu. The verb let, which allows for LDA and has been shown by Butt (1995) to be a restructuring predicate, can be passivized in Hindi-Urdu, but the embedded object of its infinitival complement cannot appear in the nominative. 
Long Distance Agreement in Hindi-Urdu

(43) [Sita-ko mujhe $/{ }^{*} m \tilde{E}$ piit-ne] di-yaa ga-yaa Sita-Dat me.Acc/I.Nom hit-Inf.Obl give-Pfv.MSg Pass-Pfv.MSg

'Sita was allowed to hit me.' (= 'Someone let Sita hit me.')

The unacceptability of the embedded object appearing in the nominative indicates that restructuring infinitives in Hindi-Urdu do not have a structure where they do not license accusative. If they did, we would expect the embedded object to appear in the nominative.

The structures I adopt for restructuring and non-restructuring infinitival complements of verbs like chaah 'want' differ in whether they involve the projection of a PRO subject.

a. Hindi-Urdu Restructuring Infinitive:

[Subject [v [ ${ }_{V P} \mathrm{~V}_{R V}\left[\operatorname{Inf}^{0}\left[{ }_{v P} \mathrm{v}\left[{ }_{V P} \mathrm{~V}\right.\right.\right.$ OBJ] $\left.\left.\left.]\right]\right]\right]$

b. Hindi-Urdu Non-Restructuring Infinitive:

[Subject [v [ ${ }_{V P} \mathrm{~V}_{N R V}\left[\operatorname{Inf}^{0}{ }_{v P} \mathrm{PRO} \mathrm{v}\left[{ }_{V P} \mathrm{~V}\right.\right.$ OBJ]]]]]]

We can now motivate an assumption we made earlier concerning the role of PRO in the infinitival clause. The assumption was that the PRO was invisible for the purposes of agreement. This was why it did not serve as a closer Goal than the embedded object for the matrix $\mathrm{T}^{0}$ Probe. With the structures in (44) in hand, the invisibility of PRO follows straightforwardly. It is just not projected in a restructuring infinitive. When it is projected, as in a non-restructuring infinitive, it blocks Long Distance Agreement by functioning as a closer Goal than the embedded object. The correlation between restructuring and LDA is now related to the structure of restructuring infinitives. This structural difference between restructuring and nonrestructuring infinitives will also be relevant in our analysis of the optionality of Long Distance Agreement, as we shall see in $\S 6$.

Apart from a syntactically projected subject, non-restructuring infinitives can have additional structure. In (33b), for example, the infinitival clause is overtly case marked suggesting the presence of additional syntactic structure. Restructuring infinitives, how- 
ever, never have additional structure. This helps derive a generalization noted in Hook (1979:29) and Butt (1995:78) that LDA is not possible out of an overtly case-marked infinitival clause. The presence of the case-marking implicates additional structure, which in turn rules out the restructuring and therefore LDA.

\subsection{INFINITIVES AND GERUNDS}

This is good point to add to the discussion the fact that infinitival clauses in Hindi-Urdu have nominal properties. Butt $(1993,1995)$ gives many arguments for analyzing HindiUrdu infinitival clauses as noun phrases. These arguments are based on the isomorphy of infinitival and nominal morphology and the ability of infinitival verbs to receive casemarking, among others. I accept the basic thrust of Butt's arguments but I believe her conclusion that all infinitival clauses in Hindi-Urdu are NPs is too strong. The fact of the matter is that there is no morphological distinction between gerunds and infinitivals in Hindi-Urdu. This does not mean that a form with gerundive/infinitival morphology is necessarily a gerund (i.e. an NP). The facts from LDA provide a way to distinguish between gerunds and infinitivals. Gerunds like NPs have $\phi$-features of their own even though these features may be default features. Infinitivals on the other hand do not have valued features of their own. They may, however, have their features covaluated by a higher finite $\mathrm{T}^{0}$ head.

One way to force a gerundive analysis is to examine structures with internally caselicensed genitive subjects. Genitive subjects are found in Hindi-Urdu only in nominal environments and their presence is a reliable indicator that what we have is a gerund. If we embed an infinitival/gerundive clause with a genitive subject in an environment where LDA is otherwise possible, we find, as has been noted by Davison (1991) and Butt (1995), that Long Distance Agreement is blocked.

(45) a. Embedded infinitival clause can have a genitive subject: 
Long Distance Agreement in Hindi-Urdu

?Firoz-ne [Shabnam-kaa roții khaa-naa] chaah-aa

Firoz-Erg Shabnam-Gen bread.F eat-Inf want-Pfv.MSg

'Firoz wanted Shabnam's eating bread.'

b. LDA not possible in presence of genitive subject of infinitival clause:

*Firoz-ne [Shabnam-kaa rotii khaa-nii] chaah-ii

Firoz-Erg Shabnam-Gen bread.F eat-Inf.F want-Pfv.FSg

c. LDA possible if there is no subject:

Firoz-ne [rotii khaa-nii] chaah-ii

Firoz-Erg bread.F eat-Inf.F want-Pfv.FSg

'Firoz wanted to eat bread.'

The blocking of Long Distance Agreement can be seen as a Minimality Effect on the application of AGREE. If a maximal projection is of the kind that potentially has $\phi$-features, $\mathrm{T}^{0}$ cannot AGREE with the $\phi$-features of a maximal projection inside it.

$$
{ }^{*} \mathrm{X}^{0}[\mathrm{~B}] \ldots[A \ldots \mathrm{B} \ldots]
$$

(Both A and B are the same kind of category)

The clauses in $(45 a, b)$ are gerunds with intrinsic though default features These features block matrix $\mathrm{T}^{0}$ from participating in AGREE with an object inside the gerund. The clause in (45c) can be an infinitival and when analyzed as an infinitival clause has no intrinsic features of its own. Consequently LDA is not blocked.

\section{Crosslinguistic Extensions}

\subsection{Long Distance Agreement in Kashmiri ANd a dialect of Hindi-Urdu}

An important aspect of the Hindi-Urdu data under discussion has been the parasitic nature of infinitival agreement. This is exemplified by the contrast between (47a) and (47b). 
(47) a. infinitival agreement but no LDA:

*Shahrukh [tehnii kaat-nii] chaah-taa thaa

Shahrukh branch.F cut-Inf.F want-Pfv.MSg be.Pst.MSg

b. no LDA and no infinitival agreement:

Shahrukh [tehnii kaat-naa] chaah-taa thaa

Shahrukh branch.F cut-Inf.M want-Pfv.MSg be.Pst.MSg

'Shahrukh wants to cut the branch.'

However, there are speakers of Hindi-Urdu for whom (47a) is acceptable. Mahajan (1989:234) notes that (47a) is unacceptable for most, but not all, speakers. Davison (1988), Butt (1995), and Bickel and Yadava (2000) also report the acceptability of examples like (47a). Therefore I treat the issue of the acceptability of (47a) as one of dialectal variation.

Features that figure in dialectal variation tend to also appear in crosslinguistic variation and therefore it is not surprising that there is a closely related Modern Indo-Aryan language where the structure corresponding to (47a) is grammatical. In Kashmiri, infinitival agreement is not parasitic on Long Distance Agreement (cf. Subbarao \& Munshi 2000).

a. Infinitival Agreement, LDA

Raam-an che hameeSI yatshImatsI [panInis necivis khAAtrI koori

Ram-Erg be.Prs.F always wanted.FPl self.Dat son.Dat for girls vuchini] see-Inf.FPl

'Ram has always wanted to see girls for his son.'

b. Infinitival Agreement, no LDA

Raam-an chu hameeSI yotshImut [panInis necivis khAAtrI koori Ram-Erg be.Prs.MSg always wanted.MSg self.Dat son.Dat for girls vuchini]

see-Inf.FPl

'Ram has always wanted to see girls for his son.'

Infinitival agreement also takes place when Long Distance Agreement is not even a possibility. 
(49) (Sadaf Munshi p.c.)

a. Raam chu yatsaan [koori vuchini]

Ram be.Prs.MSg want-Impfv girls see-Inf.FPl

'Ram wants to see the girls.'

b. Zoon che yatsaan [koori vuchini]

Zoon.F be.Prs.F want-Impfv girls see-Inf.FPl

'Zoon wants to see the girls.'

In $(49 a, b)$, the matrix subject gets Nominative case and therefore the verb agrees with it. Consequently, there is no room for the infinitival object to display Long Distance Agreement with the matrix verb. However, this does not block the object from agreeing with the infinitival verb.

\subsubsection{Butt (1995)'s analysis of Long Distance Agreement}

Butt (1995) proposes an analysis of Long Distance Agreement for a dataset where LDA is not parasitic, i.e. (47a) is grammatical. Since Butt's (1995) analysis seems to extend to the Kashmiri data, I introduce her proposal before going on to my own analysis of Kashmiri and the relevant Hindi-Urdu dialect. Davison's (1991) analysis of LDA seems to make the same predictions as Butt (1995) and therefore in the interest of brevity it is not summarized separately.

Butt (1995)'s analysis of LDA reduces LDA to two instances of local agreement. The first instance involves agreement between object of the embedded infinitival clause and the infinitival verb and the second instance involves agreement between the infinitival clause and the matrix verb.

(50) Salman-ne [roții khaa-nii] chaah-ii

Salman-Erg bread.F eat-Inf.F want-Pfv.FSg

'Salman wanted to eat the bread.'

As noted in $\S 4.3$, Butt argues that the infinitival clause in Hindi-Urdu is really a gerund. Thus it is possible for it to have $\phi$-features. It does not have $\phi$-features of its own but it can 
acquire $\phi$-features by agreement with its highest non-overtly case-marked argument. ${ }^{8}$ In (50), this is rotii 'bread' and so the infinitival verb comes to have the $\phi$-features of its object, namely [FSg]. Since the infinitival clause is a nominal complement of the main verb, and moreover the only non-overtly case-marked one with $\phi$-features, the main verb agrees with it and comes to have the $\phi$-features [FSg]. Thus in two steps, the matrix verb comes to agree 'long distance' with the object of the infinitival clause. Note that for Butt, the agreement of the embedded object with the infinitival verb is independent of whether the infinitival verb then agrees with the matrix verb or not. This allows her to handle a Hindi-Urdu dialect where infinitival agreement is not dependent upon matrix agreement. But for the same reason, it is unable to handle the dialect where infinitival agreement is parasitic on matrix agreement.

Butt derives the optionality of Long Distance Agreement by arguing that Hindi-Urdu has an optional rule of Noun Incorporation in the sense of Mohanan (1995). Incorporation is taken by Butt to block agreement between the object and the infinitive, and consequently between the infinitive and the main verb. In other words, when there is incorporation, there is no Long Distance Agreement. As we will see in $\S 6.4$, this proposal correlating the absence of LDA with incorporation has desirable semantic consequences. However, this explanation for optionality is problematic because Noun Incorporation does not by itself provide an explanation for the optionality of Long Distance Agreement. Mohanan (1995) and Wescoat $(2000,2001)$ point out that Incorporation of the sort that they assume does not block agreement - it seems to not affect agreement at all. Consider (51a, b), which Mohanan (1995) argues involve obligatory incorporation of the object.

${ }^{8}$ Like Mahajan (1989), Butt (1995) also needs to make an assumption that we can call 'the PRO invisibility' assumption. It is important for Butt that the object is the structurally most prominent non-overtly casemarked argument in the embedded clause. If the PRO was visible, then it would be the most prominent argument and the infinitival verb would agree with it. 
a. Anil-ne larke dekh-e/ *dekh-aa Anil-Erg boys.M see-Pfv.MPl/ see-Pfv.D

'Anil saw boys.'

b. Anil-ne larkiyã: dekh-ĩ:/ *dekh-aa

Anil-Erg girls.Pl see-Pfv.FPl/ see-Pfv.D

'Anil saw girls.'

The fact that a (putatively) incorporated NP can agree plays an important role in Mohanan (1995) and Wescoat (2000, 2001)'s analyses of Noun Incorporation in Hindi. These analyses postulate multiple levels of representation - on the level where agreement relationships are represented, the NP is not incorporated.

\subsubsection{Handling Kashmiri LDA}

Because infinitival agreement in Kashmiri is independent of matrix agreement, it seems to be a language where Butt (1995)'s analysis would make exactly the right predictions: the infinitival verb would agree locally with the embedded object and acquires its features, and then the matrix predicate agrees with the infinitival clause giving us the appearance of Long Distance Agreement. However, closer examination of the data reveals that the facts are more complicated than Butt's analysis would predict. In Kashmiri, we find that infinitival verbs agree with their objects (if non-overtly case-marked) quite generally.

(52) (from Wali \& Koul 1997)

a. [mohnIn' yi philim vuchIn'] chu mumkin Mohan-Gen-FSg this film.FSg see-Inf.FSg be.Prs.MSg possible 'Mohan's seeing this film is possible.'

b. [mohnIn' kita:b tsu:ri nin'] chu ha:ra:nkun Mohan-Gen-FSg book.FSg steal-Inf.FSg be.Prs.MSg surprising

'Mohan's stealing the book is surprising.'

These are environments where in Hindi-Urdu the infinitival clause was argued to be a gerund and where Long Distance Agreement was noted to be impossible. It turns out 
that Long Distance Agreement is impossible in environments like (52) in Kashmiri too. This is not what we expect if we assume Butt's analysis. According to Butt's analysis, the matrix verb should agree with the infinitival clause, i.e. there should be Long Distance Agreement yielding the ungrammatical (53).

(53) (Sadaf Munshi p.c.)

a. *[mohnIn' yi philim vuchIn'] che mumkin Mohan-Gen-FSg this film.FSg see-Inf.FSg be.Prs.FSg possible

b. *[mohnIn' kita:b tsu:ri nin'] che ha:ra:nkun Mohan-Gen-FSg book.FSg steal-Inf.FSg be.Prs.FSg surprising

The facts from Kashmiri (and the dialect of Hindi-Urdu discussed by Butt) can be explained if we assume that $\operatorname{Inf}^{0}$ in Kashmiri (but not in the dialect of Hindi-Urdu discussed in the rest of the paper) functions as a Probe for AGREE. This is shown by the fact that infinitival agreement in Kashmiri is not parasitic on Long Distance Agreement. After entering into AGREE $\operatorname{Inf}^{0}$ cannot by itself trigger further agreement on a higher $\mathrm{T}^{0}$ because the features on $\operatorname{Inf}^{0}$ are uninterpretable, and by the definition of AGREE a Probe can only use interpretable features to value its unvalued features. Further for the reasons pertaining to restructuring discussed in $\S 4.2 .2$, the Probe $\mathrm{T}^{0}$ is unable to see the object inside the infinitival subject in (52). Therefore the object cannot function as a Goal for the matrix $\mathrm{T}^{0}$ Probe and the matrix $\mathrm{T}^{0}$ Probe cannot use the interpretable features of the object to value its unvalued agreement features (cf. the ungrammaticality of Long Distance Agreement in (53)).

Let us also examine how Long Distance Agreement takes place in Kashmiri (cf. 48a). Inf $^{0}$ in Kashmiri functions as a Probe. It identifies the embedded object as a Goal and uses its interpretable $\phi$-features to value its unvalued $\phi$-features. Once the features of $\operatorname{Inf}^{0}$ have been valued, they are eliminated from narrow syntax. Next matrix $\mathrm{T}^{0}$ functions 
as a Probe. The matrix subject is ergative, i.e. overtly case-marked so it is invisible for the purposes of AGREE. $\operatorname{Inf}^{0}$ no longer has any agreement features, interpretable or uninterpretable. This is why $\operatorname{Inf}^{0}$ does not block matrix $\mathrm{T}^{0}$ from probing further for an appropriate Goal. An additional reason that $\operatorname{Inf}^{0}$ does not block matrix $\mathrm{T}^{0}$ from probing further for an appropriate Goal is that $\operatorname{Inf}^{0}$ is not $\phi$-complete - it does not have person features. The embedded object is found next. It has interpretable features and can function as a Goal. The Probe therefore enters into an AGREE relationship with it and uses the Goal's interpretable features to value its own unvalued agreement features yield Long Distance Agreement.

It can be concluded therefore that despite initial appearances the Kashmiri Long Distance Agreement data does not provide support to Butt's analysis of Long Distance Agreement. The central and attractive idea behind Butt's analysis is that Long Distance Agreement can be reduced to a series of short distance agreements. Earlier in this paper, it was demonstrated that the facts from the dialect of Hindi-Urdu discussed in this paper cannot be explained by Butt's analysis. The facts from Kashmiri (and the dialect of Hindi-Urdu discussed by Butt) still seemed to be compatible with her analysis. A closer examination of the facts of Kashmiri revealed that Long Distance Agreement was possible in exactly those environments where it was predicted by our analysis and impossible in certain environments where Butt's analysis predicts it to be possible. ${ }^{9}$ The difference between Hindi-Urdu and Kashmiri was reduced to the nature of infinitival agreement in the two languages. In Kashmiri infinitival agreement is obligatory while in Hindi-Urdu it is parasitic on Long Distance Agreement. Regardless of the language, agreement is only possible with an XP that has its own $\phi$-features and not one that has itself acquired its $\phi$-features by agreement.

\footnotetext{
${ }^{9}$ Because the facts for the data corresponding to the crucial Kashmiri facts in (53) in the relevant HindiUrdu dialect are not available to me, the scope of my conclusion is limited to Kashmiri.
} 


\subsection{Long Distance Agreement in Tsez}

Polinsky and Potsdam (2001) discuss a case of Long Distance Agreement found in the Nakh-Daghestanian language Tsez. Long Distance Agreement in Tsez has properties that are significantly different from Hindi-Urdu Long Distance Agreement. However, the operation AGREE used to derive agreement in Hindi-Urdu is able to derive Long Distance Agreement in Tsez also.

Long Distance Agreement in Tsez differs from the Hindi-Urdu pattern in two important ways. The embedded clause is a finite clause and the NP that triggers long distance agreement can be either an embedded subject or an embedded object.

(54) (ex. 48 from Polinsky and Potsdam (2001))

a. Embedded object triggers agreement:

eni-r [už-ā magalu b-āc'-ru-łi] b-iy-xo mother-Dat boy-Erg bread.III.Abs III-eat-PSTPRT-NMLZ III-know-Prs

'The mother knows the boy ate the bread.'

b. Embedded subject triggers agreement:

eni-r [uži $\quad \phi$-āy-ru-łi] $\quad \phi$-iy-xo

mother-Dat boy.I.Abs I-arrive-PSTPRT-NMLZ I-know-Prs

'The mother knows the boy arrived.'

In addition, Polinsky and Potsdam (2001) demonstrate that the agreement trigger in Tsez has to be an embedded topic, which undergoes covert movement to the edge of a Topic Phrase as shown in (55).

(55) (ex. 94 from Polinsky and Potsdam (2001))

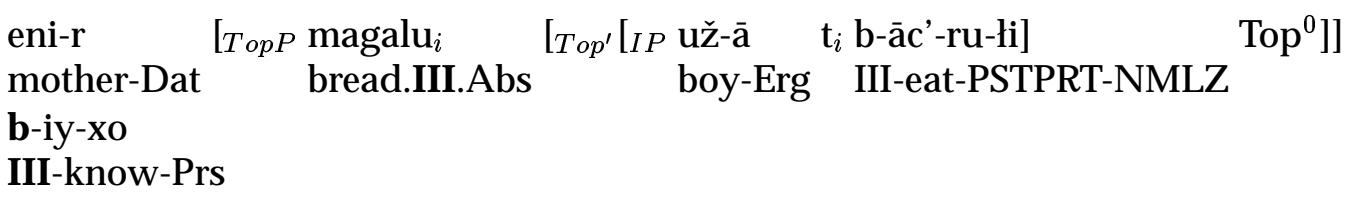

'The mother knows the boy ate the bread.' 
Long Distance Agreement in Hindi-Urdu

The matrix predicate head-governs the embedded topic in (55) and Polinsky and Potsdam (2001)) take this configuration to be the one relevant for Long Distance Agreement. ${ }^{10}$ Though the facts of Tsez Long Distance Agreement are complex, it seems that AGREE can derive them. Let us assume that as in Hindi-Urdu, matrix finite $\mathrm{T}^{0}$ has unvalued $\phi$ features and serves as a Probe. Again as in Hindi-Urdu, only the $\phi$-features of absolutive (non-overtly case-marked) arguments are visible. For this reason, the dative subject eni$r$ 'mother-DAT' is unable to value $\mathrm{T}^{0}$ 's features. $\mathrm{T}^{0}$ 's probes further. Now there is an important difference with Hindi-Urdu. As shown by the clause-internal licensing of an overt subject, the embedded clause is a finite clause with its own finite $\mathrm{T}^{0}$. We know from the discussion in $\S 4.1$ that in Hindi-Urdu matrix $\mathrm{T}^{0}$ cannot enter into an AGREE relation with an argument of an embedded finite clause. How then do we get Long Distance Agreement?

Polinsky and Potsdam's (2001) demonstration that topics in Tsez obligatorily move covertly to the edge of a Topic Phrase that dominates the IP and that only embedded topics trigger Long Distance Agreement provides an answer to the above question. The embedded agreement trigger, an object in (54a), moves to the edge of the Topic Phrase. In this position, it is visible to the matrix $\mathrm{T}^{0}$. Consequently matrix $\mathrm{T}^{0}$ can enter into an AGREE relationship with the object in (54a). In case the embedded object is not a topic, it does not move to the edge of the TopP. Then for the reasons noted in $\S 4.1$, the embedded object is not visible to the matrix $\mathrm{T}^{0}$ and there can be no AGREE relationship between the two. This point is demonstrated by (56).

(56) (ex. 64 from Polinsky and Potsdam (2001))

${ }^{10}$ Polinsky and Potsdam (2001) also suggest that Tsez Long Distance Agreement can be handled in term of Chomsky's (1999) Agree. This is unlikely to be the case for reasons that will be discussed in $\S 7.2$. 
babi-r [kidb-ā eni-r kumek b-oy-xosi-łi]

father-Dat girl-Erg mother-Dat help.III.Abs III-make-PRSPRT-NMLZ.IV

r-iyxo/ ${ }^{*} \mathbf{b}$-iyxo

IV-knows/III.knows

'The father knows that the girl is helping the mother.'

The noun kumek 'help' that triggers local agreement is part of a light verb $(\mathrm{N}-\mathrm{V})$ construction. It does not refer and cannot serve as a topic. It does not move to [Spec,TopP] and consequently it is unable to trigger Long Distance Agreement.

There is much more to Polinsky and Potsdam's (2001) analysis of Tsez Long Distance Agreement. What is important here is that their insights and explanations are fully compatible with a system that involves the operation AGREE.

\section{What about Optionality?}

\subsection{OPTIONALITY}

One aspect of Long Distance Agreement that has been much noted is its optionality in cases like (57) and (58).

(57) (from Mahajan 1989)

a. LDA:

Ram-ne [roṭii khaa-nii] chaah-ii

Ram-Erg bread.F eat-Inf.F want-Pfv.FSg

'Ram wanted to eat bread.'

b. no LDA:

Ram-ne [roții khaa-naa] chaah-aa

Ram-Erg bread.F eat-Inf.M want-Pfv.MSg

'Ram wanted to eat bread.'

(58) (from Butt 1995) 
a. LDA:

Nadia-ko [gaarii chalaa-nii] aa-tii hai

Nadia-Dat car.F drive-Inf.F come-Hab.F be.Prs.Sg

'Nadia knows how to drive a car.'

b. no LDA:

Nadia-ko [gaarii chalaa-naa] aa-taa hai

Nadia-Dat car.F drive-Inf.M come-Hab.M be.Prs.Sg

'Nadia knows how to drive a car.'

From the perspective of the overall Hindi-Urdu agreement system, the optionality found with Long Distance Agreement in (57) and (58) is unexpected. There is no optionality in cases of local agreement. If the verb can agree with one of its arguments, then it must agree with that argument.

(59) Local Agreement: No Optionality

a. Subject Agreement

Mona amruud khaa-tii $/{ }^{*}$-taa thii $/{ }^{*}$ thaa

Mona.F guava.m eat-Hab.F/-Hab.m be.Pst.F/be.Pst.MSg

'Mona used to eat guavas.'

b. Object Agreement

Mohan-ne imlii khaa-ii/*-yaa thii /*thaa

Mohan.M-Erg tamarind.F eat-Pfv.F/-Pfv.MSg be.Pst.F/be.Pst.MSg

'Mohan had eaten tamarind.'

c. Default Agreement

Mona-ne maalaa-ko uthaa-yaa ${ }^{*}$-ii thaa $/{ }^{*}$ thii

Mona.F-Erg necklace.F-Acc lift-Pfv.Def/-Pfv.FSg be.Pst.MSg/be.Pst.FSg

'Mona lifted the necklace.' 


\subsection{DERIVING OPTIONALITY}

To derive the optionality of Long Distance Agreement, we need an optional element somewhere. Mahajan (1989) had infinitives optionally assigning case and Butt (1995) had optional incorporation. These devices have been argued against.

I propose that the optionality found with Long Distance Agreement can be reduced to the well-known optionality of Restructuring. In particular certain verbs that take restructuring infinitives as complements can also take non-restructuring infinitives as complements. It has already been argued in $\S 4.2$ that the class of verbs that allow for Long Distance Agreement out of their complements are restructuring predicates. In what follows I will relate the optionality of LDA with predicates like chaah 'want' and $a a$ 'come' to these verbs optionally taking a non-restructuring complement. Following the discussion in $§ 4.2 .2$, we know that Long Distance Agreement is not possible out of non-restructuring infinitives. Restructuring infinitives and non-restructuring infinitives differ in whether they have a syntactically projected PRO subject.

a. Restructuring Infinitive, $\operatorname{LDA}^{0} \mathrm{~T}^{0}[\mathrm{~A}] \ldots . . .\left[\operatorname{Inf}^{0}[\mathrm{~A}] \ldots . \mathrm{DP}[\mathrm{A}]\right]$

Ram-ne [mujhe kahaanii sun-aa-nii] chaah-ii thii

Ram-Erg I.Dat story.F hear-CAUS-Inf.F want-Pfv.F be.Pst.FSg

'Ram had wanted to tell me a story.'

b. Non-restructuring Infinitive, no LDA: $\mathrm{T}^{0}[\mathrm{D}] \ldots . . .\left[\operatorname{Inf}^{0}[\mathrm{D}] \mathrm{PRO}[\mathrm{D}] \ldots . \mathrm{DP}[\mathrm{A}]\right]$

Ram-ne [PRO mujhe kahaanii sun-aa-naa] chaah-aa

Ram-Erg I.Dat story.F hear-CAUS-Inf.MSg want-Pfv.MSg thaa

be.Pst.MSg

'Ram had wanted to tell me a story.'

The presence of a PRO in the non-restructuring infinitive blocks the AGREE relationship between the matrix $\mathrm{T}^{0}$ and the embedded object. Restructuring infinitives do not have an intervening PRO subject, the embedded object is visible to AGREE, and therefore there 
Long Distance Agreement in Hindi-Urdu

is Long Distance Agreement. There is no longer any optionality in Agreement. There are just two different structures. The structure in (60a) involves a PRO-less infinitival clause and therefore given the rest of the syntactic environment, it must have Long Distance Agreement. (60b) involves a PRO intervening between the matrix $\mathrm{T}^{0}$ and the embedded object, which cannot therefore trigger Long Distance Agreement.

In addition to the optionality of restructuring, there is one more source for the optionality of Long Distance Agreement. It has been argued in $\S 4.3$ that Long Distance Agreement is not possible out of gerunds. It was also noted there that given the syncretism between infinitival and gerundive morphology in Hindi-Urdu, there is no reason why the nonfinite complement in $(60 \mathrm{~b})$ cannot be analyzed as a gerund. But then the absence of Long Distance Agreement in (60b) would follow from the impossibility of Long Distance Agreement out of a gerund.

This proposal correlating the availability of non-restructuring analysis - be it a nonrestructuring infinitive or a gerund - receives support from two kinds of facts. First in $\S 6.3$, we see that cases where restructuring is obligatory display obligatory Long Distance Agreement. Then in $\S 6.4$, we see the second kind of evidence which concerns the interpretive effects of Long Distance Agreement.

\subsection{Obligatory Instances of Long Distance Agreement}

The logic of this section is as follows. In the preceding discussion, we have identified optional restructuring as the source of optional Long Distance Agreement. To argue for this relationship, we examine environments which have been argued to involve obligatory restructuring and show that in these environments Long Distance Agreement is also obligatory. Two such environments include the 'permissive' construction and the complements of modal verbs. 
Butt (1995) analyzes the examples in (61), which she calls the Permissive, and shows that they involve obligatory restructuring (in her terms, complex predicate formation). Independently of Butt's (1995) diagnostics, we can see that the permissive involves caselicensing across the infinitival clause boundary.
a. Nadia-ne [per kat-ne] di-ye Nadia-Erg trees cut ${ }_{\text {Intr }}$-Inf.Obl let-Pfv.Pl
'Nadia let the trees get cut.'
b. Nadia-ne [Sarosh-ko gaarii chalaa-ne] di-i Nadia-Erg Sarosh-Acc car.F drive-Ger.Obl let-Pfv.FSg
'Nadia let Sarosh drive the car.'

The subject of the infinitival clause is assigned case in both (61a) and (61b) is licensed by the matrix verb. There is no source for case to the embedded subject within the infinitival clause. Given that the permissive must involve case-licensing across a case boundary, we expect Long Distance Agreement to be obligatory and as an anonymous reviewer pointed out to me, this is in fact the case. ${ }^{11}$

The facts with modals are similar. The subject of the infinitival complement of the modal is case-licensed outside the infinitival clause, there being no source for subject case within an infinitival clause. Following the previous discussion, we can take this to demonstrate that restructuring is obligatory. Then as expected, we find that Long Distance Agreement is obligatory.

\footnotetext{
11 The facts are actually slightly more complicated. Some speakers distinguish between (61a) and (61b), finding LDA obligatory in (61a) but not in (61b). The generalization for these speakers seems to be that agreement of $\mathrm{T}^{0}$ with elements case-licensed by it or its associated $v$ is obligatory, but agreement beyond that is optional. Note that in (61a) the case of the agreeing element is licensed by the matrix $v$. This is not the case in (61b).
} 
a. Ram-ko ${ }_{i}\left[\mathrm{t}_{i}\right.$ davaaii khaa le-nii/*le-naa] chaahiye Ram-Dat medicine.F eat TAKE-Inf.F/TAKE-Inf.MSg should thii /*thaa be.Pst.FSg/ ${ }^{*}$ be.Pst.MSg

'Ram should have eaten the medicine.'

b. kapre $_{i} \quad\left[\mathrm{t}_{i}\right.$ aaj-tak ban jaa-ne/*jaa-naa $]$ chaahiye clothes.MPl today-by make ${ }_{\text {Intr }}$ GO-Inf.MPl/GO-Inf.MSg should the ${ }^{*}$ thaa be.Pst.MPl/*be.Pst.MSg

'The clothes should have been made by today.'

\subsection{The Interpretive EfFects of Long Distance Agreement}

The presence of Long Distance Agreement has been noted in the literature to have certain interpretive effects. Hook (1979:30) writes:

After having said all this about agreement at a distance, it must be recognized that not all speakers observe it to the same degree. .... For some speakers there is a difference in meaning: Observing agreement at a distance puts emphasis on the object. Nonobservance suggests a more general activity.

He contrasts (63a) with (63b), noting that (63a) involves a less specific action than (63b).

a. No LDA:

us-ne [kursiyã: tor-naa] shuruu ki-yaa he-Erg chairs.FPl break-Inf.MSg start do-Pfv.MSg

'He began breaking chairs.'

b. LDA:

us-ne [merii aaraam-kursii tor-nii] shuruu ki-i he-Erg my.F rest-chair.FSg break-Inf.F start do-Pfv.FSg 'He began breaking my easy chair.'

The general claim, following Hook (1979:30) in Davison (1988) and Butt (1995), is that embedded objects that agree long distance with the matrix predicate are more specific 
than embedded objects that do not. This claim seems to be on the right track but the lack of a concrete denotation for the term 'specific' makes it hard to assess this claim. Mahajan (1989) provides a clearer proposal when he relates the presence of long distance agreement with wide scope over the matrix predicate. Consider the following contrast.

(64) (from Mahajan (1989), = 57)

a. LDA

Ram-ne [rotii khaa-nii] chaah-ii

Ram-Erg bread.F eat-Inf.F want-Pfv.FSg

'Ram wanted to eat bread.'

b. no LDA:
Ram-ne [rotii khaa-naa] chaah-aa
Ram-Erg bread.F eat-Inf.M want-Pfv.MSg
'Ram wanted to eat bread.'

Mahajan (1989) notes “(64a) has a clear interpretation in which roții 'bread' is interpreted outside the intension of the matrix verb chaah 'want', i.e. there is a particular rotii 'bread' that Ram wants to eat. This interpretation is missing in (64b), the case which does not involve long distance agreement."

The above quote from Mahajan (1989) leaves open the question of whether Long Distance Agreement forces the object to take wide scope over the matrix verb or whether it merely favors it. There seems to be considerable evidence that while Long Distance Agreement favors wide scope of the object over the matrix predicate, it does not force a wide scope reading. This is shown by the fact that objects that cannot easily have referential readings are able to participate in Long Distance Agreement. In particular, objects of verbs of creation as well as nouns occurring in light verb $(\mathrm{N}-\mathrm{V})$ constructions do not have referential interpretations. (65) shows that such NPs can still trigger long distance agreement. See Davison (1991) for related examples. 
Long Distance Agreement in Hindi-Urdu

(65) a. Object of Verb of Creation:

Usha-ne [potluck ke-liye daal banaa-nii] chaah-ii thii

Usha-Erg potluck for lentil.F make-Inf.F want-Pfv.F be.Pst.FSg

'Usha had wanted to prepare lentils for the potluck.'

b. Nouns in Light Verb (N-V) Constructions:

Akbar-ne [merii madad kar-nii] chaah-ii thii

Akbar-Erg my.F help.F do-Inf.F want-Pfv.F be.Pst.FSg

'Akbar had wanted to help me.'

The possibility of Long Distance Agreement with the non-referential madad 'help' in (65b) is particularly striking and conclusively show that Long Distance Agreement does not enforce referential interpretation. Polinsky and Potsdam (2001) argue that any argument that triggers Long Distance Agreement in Tsez must be interpreted as an embedded topic and they note that nouns occurring in light verb constructions (similar to (65b)) cannot trigger Long Distance Agreement (cf. 56).

It is also useful to look carefully at the claim that the absence of Long Distance Agreement forces a narrow scope reading. From the work of Dayal (1999, to appear), we know that bare singulars in Hindi-Urdu can be interpreted in two ways: as definites, and as narrow scope 'incorporated' NPs. Given this one might expect structures like Mahajan's (64) which involve bare singulars to permit definite readings even in the absence of Long Distance Agreement and this seems to be true. Imagine a context where there is a newspaper and a book on a table near Ram. If Ram wants to pick up the book, both the version with and without Long Distance Agreement seem suitable to describe this desire about a particular book.

(66) Ram-ne [kitaab uthaa-naa] chaah-aa/uthaa-nii] chaah-ii Ram-Erg book.F lift-Inf.MSg want-Pfv.MSg/want-Pfv.F want-Pfv.FSg

'Ram wanted to pick up the book.' 
To make the facts sharper, let us therefore look at the scopal interaction of quantificational expressions and the intensional verb in (67). Both $(67 a, b)$ allow for the reading where 'every book' scopes under 'want' i.e. Naim's desire is to read every book. However, (67a) also allows for the reading where Naim does not have the express desire to read every book (in the library) - it is just that for every book in the library he has expressed his desire to read it. For this reading he need not know that he has in fact exhausted the books in the relevant set. This reading is absent in $(67 \mathrm{~b}){ }^{12}$

a. LDA:

Naim-ne [har kitaab parh-nii] chaah-ii thii

Naim-Erg every book.F read-Inf.F want-Pfv.F be.Pst.FSg

every > want: For every book, Naim wanted to read it.

want > every: Naim's desire: to read every book

b. no LDA:

Naim-ne [har kitaab parh-naa] chaah-aa thaa

Naim-Erg every book.F read-Inf.MSg want-Pfv.MSg be.Pst.MSg

want > every: Naim's desire: to read every book

Unavailable: every > want: For every book, Naim wanted to read it.

The facts concerning the interpretive effects of Long Distance Agreement in Hindi-Urdu can now be spelled out as follows: for some speakers, the absence of Long Distance Agreement blocks a reading for the object where it takes wide scope over the matrix predicate. Long Distance Agreement makes such a reading available but does not enforce it.

The following is a preliminary and admittedly speculative attempt to derive the semantic effects of Long Distance Agreement. It tries to make explicit the intuition that whatever it is about nonrestructuring infinitives that blocks Long Distance Agreement also blocks

${ }^{12}$ For some speakers this contrast is only a preference, for others it is not very strong and one of the reviewers does not get this contrast at all. 
Long Distance Agreement in Hindi-Urdu

covert movement out of the infinitival clause. Long Distance Agreement involves restructuring infinitives. If we can motivate that restructuring infinitives allow for, but do not require, optional covert movement of the object out of the infinitival clause to a position above the matrix predicate, we can explain the observed ambiguities. The absence of Long Distance Agreement indicates a non-restructuring infinitive or a gerund. Further if we can motivate that non-restructuring infinitives/gerunds block covert movement of the object, we can also explain why the wide scope reading is blocked. My explanation uses a proposal put forth in Fox (2000:62) to account for the clause-boundedness of QR. According to Fox's (2000) principle of Scope Economy, any string-vacuous/covert operations is only permitted if its application has an effect on the interpretation.

a. Hindi-Urdu Nonrestructuring Infinitive:

[Subject $\left.\left[{ }_{v P}\left[V_{V P}\left[{ }_{I P}\left[{ }_{v P} \operatorname{PRO}\left[{ }_{v^{\prime}}\left[{ }_{V P} \mathrm{OBJ} \mathrm{V}\right] \mathrm{v}\right]\right] \mathrm{Inf}^{0}\right] \mathrm{V}\right] \mathrm{v}\right]\right]$

b. Hindi-Urdu Restructuring Infinitive:

[Subject $\left.\left[{ }_{v P}\left[V_{V P}\left[I P\left[{ }_{v P}\left[V_{P} \mathrm{OBJ} \mathrm{V}\right] \mathrm{v}\right] \operatorname{Inf}^{0}\right] \mathrm{V}\right] \mathrm{v}\right]\right]$

The presence of a PRO in (68a) blocks the embedded object in place because the QR of the embedded object over the PRO would be semantically vacuous and hence ruled out by Scope Economy. The blocking of this first step then rules out further covert movement of the object over the matrix verb. In (68b), with a PRO subject absent, the first step of QR of the embedded object is over the embedding predicate and is not semantically vacuous. Consequently it is not blocked by Scope Economy. 


\section{Empirical Extensions and Theoretical Implications}

\subsection{EMPIRICAL EXTENSIONS}

In this section, I will briefly outline some further directions that the line of inquiry pursued in this paper could be taken in.

\subsubsection{A Generalization about Person}

Object agreement in Hindi-Urdu only involves agreement in number and gender and not in person, while subject agreement can involve agreement in person, number, and gender. If we distinguish between two kinds of Agreement: dissociated agreement, where a head agrees with an XP whose case it does not license (= object agreement on $\left.\mathrm{T}^{0}\right)$ and nondissociated agreement, where a head agrees with an XP whose case it does license, we can state the following generalization:

(69) Person Generalization: Dissociated Agreement does not involve Person.

Further if we assume that subject agreement in Hindi-Urdu involves overt movement to the $[\mathrm{Spec}, \mathrm{TP}]$ while object agreement takes place via AGREE alone, then it becomes tempting to relate person agreement to overt movement (cf. Boeckx (2003) for a similar generalization motivated by Icelandic data).

However, a simpler explanation is available for the absence of person agreement with object agreement in Hindi-Urdu. Proper name and pronominal objects in Hindi-Urdu must be overtly case-marked with -ko and the presence of -ko blocks agreement. Thus the only objects that can in principle agree are 3rd person non-pronominal DPs. Since 1st and 2nd person objects cannot appear with overt case-marking, we do not find any instances of object agreement involving 1st or 2nd person features.

Kashmiri seems to be a minimal pair to Hindi-Urdu - 1st and 2nd person objects appear without overt case-marking, and we find person agreement with objects. 
(70) (from Wali and Koul (1997))

aslam-an vuch-u-kh tsI

Aslam-Erg saw-MSg-2Sg you.MSg

'Aslam saw you.'

I write 'seems to' because Kashmiri has an additional system of pronominal clitics (see Hook and Koul (1984) and Wali and Koul (1997)) and a good case can be made that the person agreement we see in (70) is part of the pronominal clitic system and not the agreement system.

The facts from Gujarati are more telling. As noted in $§ 3.2 .2$, overtly case-marked objects are still visible to the agreement system in this language. However, the present tense auxiliary which does display agreement in person with subjects does not agree with the object in person.

(71) a. Present tense auxiliary agrees with second person subject:

tEhme aw-yā cho

you.Pl come-Pfv.MPl be.Prs.2Pl

'You have come.'

b. Present tense auxiliary does not agree with second person object: (from Magier $(1983: 324))$

mãĩ tam-ne mār-yā che

I you.Pl-Acc strike-Pfv.MPl be.Prs.3

'I have struck you.'

To sum up, the facts from the Modern Indo-Aryan languages support the Person Generalization. 


\subsubsection{Scrambling, Case, and Adjuncts}

Agreement in Hindi-Urdu as well as in other Modern Indo-Aryan languages does not seem to be affected by word order. Structures involving long and short distance scrambling as well as rightward movement display the same agreement pattern as the 'basic' structure. A straightforward way of handling this non-interaction is to assume that scrambling and other non-case-related movements take place after AGREE has applied. An implication then is that the current proposal is not directly compatible with a structure building model that interleaves case-related movements with non-case-related movements. A way out would be to adopt the proposals like Dayal (1994) and Kidwai (2000) which argue contra Mahajan (1990a) that scrambling always involves $A^{\prime}$-movement. Then if only A-related elements are visible to AGREE (when involved in the valuation of $\phi$-features), the non-interaction between scrambling and agreement would follow. Something like this seems independently necessary given that bare-NP adjuncts as well as NPs that function as predicate nominals do not trigger agreement.

\subsection{AGREE AND AGREE}

The operation Agree introduced in Chomsky (1999) and the operation AGREE have several important similarities. They both involve a Probe which has unvalued features. This Probe seeks a Goal which has features that can value the unvalued features of the Probe. In addition the Goal has to be in the c-command domain of the Probe and the search for the Goal has to obey locality considerations.

The two operations, however, diverge on the requirements they put on the Goal. The Goal for Agree has to be active, where by active we mean that the Goal has unvalued features. The intuition behind this aspect of Agree is that once the unvalued Case features of a DP have been valued, the DP is frozen in place as far as the A-system is concerned. A DP whose unvalued case features have been valued cannot move further and satisfy the 
OCC feature of a higher head. If this was possible, we would be able to generate certain illegitimate instances of raising.

(72) a. ${ }^{*} \mathrm{John}_{i}$ is certain [ $\mathrm{t}_{i}$ will win].

b. ${ }^{*}\left[\mathrm{John}_{i}\right.$ to seem $\left[\mathrm{t}_{i}\right.$ is intelligent $]$ would be surprising.

The ungrammaticality of both $(72 a, b)$ can be attributed to the fact that the Goal of the matrix $\mathrm{T}^{0}$ is inactive. It has already had its unvalued case features valued by the embedded $\mathrm{T}^{0}$. Consequently it is no longer available for Agree (followed by subsequent Pied-Piping and Merge) by a higher head.

In contrast to Agree, it is possible for a Probe to enter into an AGREE relationship with an inactive Goal. This was the case for Long Distance Agreement in both Hindi-Urdu and Tsez. The case requirements of the agreement trigger are met in the embedded clause where it appears. It is therefore inactive. This distinction between AGREE and Agree seems crucial. If we reduce Agree to AGREE, we end up allowing for certain illegitimate instances of raising. If we reduce in the other direction, we lose our explanation for Long Distance Agreement.

I conclude this paper with a way of reconciling the above tension between AGREE and Agree. It was noted above that allowing inactive Goals to participate in Agree allowed for illegitimate instances of raising like the ones in (72). But (72) does not just involve Agree. In addition, it involves Pied-Piping followed by Merge of the inactive Goal. Therefore it is logically possible that what (72) demonstrates is not a constraint against inactive Goals participating in Agree, but is instead a constraint against Pied-Piping or Merge of inactive Goals. Then we could reduce Agree to AGREE, i.e. allow inactive Goals, but not allow inactive Goals to pied-pipe and participate in Internal Merge. In other words, inactive Goals could participate in Agree but not in Move. ${ }^{13}$ Once we adopt this assimilation of

${ }^{13}$ Lavine and Freidin (2001) and López (2002) offer independent arguments in favor of eliminating the requirement that Goals be active to participate in Agree. 
Agree and AGREE, an alternate analysis of agreement in English expletive constructions becomes available. The analysis of (73) suggested in Chomsky (2001) and much other work assumes that the associate of the expletive triggers agreement on the matrix $\mathrm{T}^{0}$ because the matrix $\mathrm{T}^{0}$ licenses the case of the expletive associate.

(73) a. There are many people in that room.

b. There seem to be many people in that room.

According to the Chomsky (2001) analysis, the matrix $\mathrm{T}^{0}$ is able to enter into Agree with the expletive associate because the expletive associate has not had its case features valued. Thus it is still active. If we drop the requirement that Agree is only possible with active Goals, other analyses become available. In particular Lasnik (1999), Ch. 3, suggests following Belletti (1988) that the case of the expletive associate is licensed independently of $\mathrm{T}^{0} \cdot{ }^{14}$ If this is the case then the Goals that trigger agreement in (73) are also inactive and we have an instance of inactive Goals triggering Agree in English also.

\footnotetext{
${ }^{14}$ In addition if we make the plausible assumption that unlike the English there, the French expletive il has $\phi$-features, we have a straightforward account for why the associate of the expletive does not trigger agreement in French.

i. (from Belletti (1988))
}

a. Trois filles sont arrivées. three girls are arrived.FPl 'Three girls arrived.

b. Il est arrivé trois filles. EXPL is arrived three girls 'There arrived three girls.'

In (i.a), the expletive $i l$ enters into Agree with $\mathrm{T}^{0}$, values its own case features, and values the unvalued agreement features of $\mathrm{T}^{0}$. The case of trois filles 'three girls' is licensed by the unaccusative verb. This account, which is quite close to the Belletti (1988)/Lasnik (1999), is superior to the Chomsky (2001) account, where the case of trois filles 'three girls' is licensed via Agree by $\mathrm{T}^{0}$. Therefore $\mathrm{T}^{0}$ must agree with trois filles 'three 


\section{References}

Aissen, Judith L. and David M. Perlmutter. 1983. 'Clause Reduction in Spanish', in D. M. Perlmutter (ed.), Studies in Relational Grammar Vol. 1, Chicago: University of Chicago Press. pp. 360-404. originally published in 1976.

Belletti, Adriana. 1988. 'The case of unaccusatives', Linguistic Inquiry 19(1), 1-34.

Benmamoun, Elabbas. 1992. 'Structural Conditions on Agreement', in K. Broderick (ed.), Proceedings of NELS 22, Amherst, Massachusetts: GLSA, pp. 17-32.

Bickel, Balthasar and Yogendra P. Yadava. 2000. 'A fresh look at grammatical relations in Indo-Aryan', Lingua 110, 343-373.

Bobaljik, Jonathan David. 1995. 'Morphosyntax: The Syntax of Verbal Inflection', Ph.D. thesis. Massachusetts Institute of Technology. Cambridge, Massachusetts. Distributed by MIT Working Papers in Linguistics.

Boeckx, Cedric. 2003. 'Intricacies of Icelandic Agreement', manuscript, University of Maryland/Harvard University.

Butt, Miriam. 1993. 'Hindi/Urdu Infinitives as NPs', South Asian Language Review: Special Issue on Studies in Hindi-Urdu, edited by Yamuna Kachru 3(1), 51-72.

Butt, Miriam. 1995. The structure of complex predicates in Urdu, Dissertations in Linguistics. Stanford, California: CSLI Publications. Doctoral thesis at Stanford University 1994.

Butt, Miriam and Tracy Holloway King. 2004. 'The Status of Case', in V. Dayal and A. Mahajan (eds.), Clause Structure in South Asian Languages, Dordrecht: Kluwer.

Cardona, George. 1965. A Gujarati Reference Grammar, Philadelphia: The University of Pennsylvania Press.

Chomsky, Noam. 1998. Minimalist Inquiries: The Framework, No. 15 in MIT Occasional Papers in Linguistics. Cambridge, MA: MITWPL.

Chomsky, Noam. 1999. Derivation by Phase, No. 18 in MIT Occasional Papers in Linguistics. Cambridge, MA: MITWPL.

Chomsky, Noam. 2001. 'Beyond Explanatory Adequacy', Unpublished manuscript, MIT.

Chung, Sandra. 1998. The Design of Agreement, Chicago: University of Chicago Press.

Comrie, Bernard. 1984. 'Reflections on Verb Agreement in Hindi and related languages', Linguistics 22, 857-864.

Davison, Alice. 1988. 'Constituent structure and the realization of agreement features', in L. Macleod, G. Larson, and D. Brentari (eds.), Papers from the 24th Regional Meeting of the Chicago Linguistics Society, Chicago: Chicago Linguistics Society. pp. 41-53.

Davison, Alice. 1991. 'Feature Percolation and Agreement in Hindi-Urdu', Paper presented at the South Asian Conference, University of Wisconsin.

Davison, Alice. 2004. 'Structural Case, Lexical Case, and the Verbal Projection', in V. Dayal and A. Mahajan (eds.), Clause Structure in South Asian Languages, Dordrecht: Kluwer.

Dayal, Veneeta. 1999. 'Bare NP's, Reference to Kinds, and Incorporation', in Proceedings of SALT IX, Cornell University, Ithaca, NY. Cornell Linguistics Club.

Dayal, Veneeta. to appear. 'Number Marking and (In)definiteness in Kind Terms', Linguistics and Philosophy 27.

Dayal, Veneeta Srivastav. 1994. 'Binding facts in Hindi and the Scrambling Phenomenon', in M. Butt, T. H. King, and G. Ramchand (eds.), Theoretical Perspectives on Word Order in South Asian Languages, No. 50 in CSLI Lecture Notes. Stanford, California: CSLI. pp. 237-262.

Deo, Ashwini and Devyani Sharma. 2002. 'Typological Variation in the Ergative Morphology of Indo-Aryan Languages', manuscript, Stanford.

Fox, Danny. 2000. Economy and Semantic Interpretation, No. 35 in Linguistic Inquiry Monographs. Cambridge, Massachusetts: MIT Press.

girls'. Since it actually does not, Chomsky (2001) needs to stipulate that the valued agreement features of $\mathrm{T}^{0}$ (showing agreement with the associate) are over-ridden by the features of $i l$. 
Hoekstra, Teun. 1994. 'HAVE as BE Plus or Minus', in G. Cinque, J. Koster, J.-Y. Pollock, L. Rizzi, and R. Zanuttini (eds.), Paths towards Universal Grammar: Studies in Honor of Richard S. Kayne, Georgetown Studies in Romance Linguistics. Washington, DC: Georgetown University Press. pp. 199-215.

Hook, Peter Edwin. 1979. Hindi Structures: Intermediate Level, No. 16 in Michigan Papers on South and SouthEast Asia. University of Michigan, Ann Arbor, Michigan: Center for South and South-East Asian Studies. Hook, Peter Edwin and Omkar N. Koul. 1984. 'Pronominal Suffixes and Split Ergativity in Kashmiri', in O. N. Koul and P. E. Hook (eds.), Aspects of Kashmiri Linguistics, No. 12 in Series in Indian Languages and Linguistics. New Delhi: Bahri Publications. pp. 123-135.

Kidwai, Ayesha. 2000. XP-adjunction in universal grammar: scrambling and binding in Hindi-Urdu, Oxford studies in comparative syntax. New York, NY: Oxford University Press.

Lasnik, Howard. 1999. Minimalist Analysis, Oxford: Blackwell Publishing.

Lavine, James E. and Robert Freidin. 2001. 'The Subject of Defective T(ense) in Slavic', Journal of Slavic Linguistics 10(1), 253-289.

López, Luis. 2002. 'On Agreement: Locality and feature valuation', in Artemis Alexiadou (ed.), Theoretical Approaches to Universals, No. 49 in Linguistik Aktuell. Amsterdam: John Benjamins. pp. 165-209.

Magier, David S.. 1983. 'Topics in the Grammar of Marwari', Ph.D. thesis. University of California, Berkeley. Berkeley, California.

Mahajan, Anoop Kumar. 1989. 'Agreement and Agreement Phrases', in I. Laka and A. K. Mahajan (eds.), Functional Heads and Clause Structure, No. 10 in MIT Working Papers in Linguistics. Cambridge, MA: MITWPL. pp. 217-252.

Mahajan, Anoop Kumar. 1990a. 'The A/A-bar distinction and Movement Theory', Ph.D. thesis. Massachusetts Institute of Technology. Cambridge, Massachusetts. Distributed by MIT Working Papers in Linguistics.

Mahajan, Anoop Kumar. 1990b. 'LF Conditions on Negative Polarity Licensing', Lingua 80(4), 333-348.

Mahajan, Anoop Kumar. 1995. 'Active Passives', in R. Aranovich, W. Byrne, S. Preuss, and M. Senturia (eds.), Proceedings of the 13th West Coast Conference on Formal Linguistics, Palo Alto: CSLI, pp. 286-301.

Mohanan, Tara. 1995. 'Wordhood and Lexicality: Noun Incorporation in Hindi', Natural Language and Linguistic Theory 13(1), 75-134.

Polinsky, Maria and Eric Potsdam. 2001. 'Long-Distance Agreement and Topic in Tsez', Natural Language and Linguistic Theory 19, 583-646.

Rizzi, Luigi. 1978. 'A Restructuring Rule in Italian Syntax', in Samuel Jay Keyser (ed.), Recent Transformational Studies in European Languages, No. 3 in Linguistic Inquiry Monographs. Cambridge, MA: MIT Press. pp. 113-158. originally published in 1976.

Subbarao, Karumuri Venkata. 2001. 'Agreement in South Asian Languages and Minimalist Inquiries: The Framework', in P. Bhaskararao and K. V. Subbarao (eds.), The Yearbook of South Asian Languages 2001, Thousand Oaks/London/New Delhi: Sage Publications.

Subbarao, K. V. and Sadaf Munshi. 2000. 'Agreement in Kashmiri and Minimalist Inquiries: the Framework', Unpublished manuscript, The University of Delhi.

van Gelderen, Elly. 1992. Verbal Agreement and the Grammar Behind Its Breakdown: Minimalist Feature Checking, Tübingen: Max Niemeyer Verlag.

Verma, Manindra Kumar and Tara Nath Sharma. 1979. Intermediate Nepali Structure Vol. 1, New Delhi: Manohar.

Wali, Kashi and Omkar N. Koul. 1997. Kashmiri: a cognitive-descriptive grammar, Descriptive Grammars. London: Routledge.

Wescoat, Michael T.. 2000. 'Hindi and the Typology of Noun Incorporation: An Analysis with Lexical Sharing', Unpublished manuscript, Stanford University.

Wescoat, Michael T.. 2001. 'On Lexical Sharing', Ph.D. thesis. Stanford University. Stanford, California. to appear.

Wurmbrand, Susanne. 1998. 'Infinitives', Ph.D. thesis. Massachusetts Institute of Technology. Cambridge, Massachusetts. Distributed by MIT Working Papers in Linguistics.

Wurmbrand, Susanne. 2001. Infinitives: Restructuring and Clause Structure, No. 55 in Studies in Generative Grammar. Berlin: Mouton de Gruyter. 
Rajesh Bhatt

University of Massachusetts at Amherst

Department of Linguistics

South College

150 Hicks Ways

Amherst, MA 01003-9274

<bhatt@linguist.umass.edu >

Date the manuscript was submitted: August 21, 2002

Date the manuscript was revised: August 9. 2004 